\title{
The application of 3D modeling and spatial analysis in the study of groundstones used in wild plants processing
}

\author{
Andrea Zupancich ${ }^{1}$ - Giuseppina Mutri ${ }^{1}$ - Isabella Caricola ${ }^{1} \cdot$ Maria Letizia Carra ${ }^{1}$ - Anita Radini ${ }^{2}$. \\ Emanuela Cristiani ${ }^{1}$ (D)
}

Received: 21 November 2018 / Accepted: 11 March 2019/Published online: 30 April 2019

(C) The Author(s) 2019

\begin{abstract}
In recent years, several works have proved the reliability of the application of 3D modeling and spatial analysis in the study of stone tool use. Monitoring surface morphometry resulting from the use of lithic tools has the potential to objectively quantify and identify patterns of modifications associated to specific activities and worked materials. In particular, the combination of surface morphometry with a systematic experimental framework and use wear analysis has the potential of foreseeing residue distribution areas over the groundstone surfaces, hence providing a key aid in establishing sampling strategies applied to archeological specimens. Here, we propose an approach that applies 3D modeling, performed through a close-range photogrammetry, and the use of GIS software to investigate surface modifications and residue distribution on groundstones used to process wild plants. Our work comprises a dedicated experimental framework in which modern tool replicas have been used to process different species of wild plant foods through grinding, crushing, and pounding. By applying 3D modeling and spatial analysis, we were able to characterize patterns of surface modifications related to each of the worked substances and activities performed. Moreover, we monitored the distribution of starch granules over the experimental groundstone surfaces and its variation in relation to the state of the worked substance and the action carried out. Our results provide one of the first experimental dataset focused on the use of groundstones for wild plant processing, and a reliable methodology for further studies related to the exploitation of stone technology and wild vegetal substances in the past.
\end{abstract}

Keywords 3D modeling · GIS · Groundstones $\cdot$ Experimental archeology $\cdot$ Residue analysis $\cdot$ Wild plants

\section{Introduction}

Functional studies, based upon use wear and residue analyses, provide essential information regarding ancient technology, as well as aspects concerning ancient human behavior and adaptive strategies. In most of the cases, functional interpretations rely on qualitative data, emerging from the microscopical identification of use wear patterns. In the last decade, numerous scholars have proposed various methods aimed to quantify use wear on knapped stone tools (Evans and Donahue 2008; GonzálezUrquijo and Ibáñez-Estévez 2003; Ibáñez et al. 2014;

Emanuela Cristiani

emanuela.cristiani@uniroma1.it

1 DANTE Diet and Ancient Technology Laboratory, Sapienza University of Rome, Via Caserta 6, 00161 Rome, Italy

2 BioArCh, Department of Archaeology, University of York, York YO10 5YW, UK
Macdonald 2014; Stemp, 2001, 2014). Among those, the application of 3D scanning and Geographic Information System (henceforth GIS) in the field of use wear analysis has recently been discussed with regard to their potential for monitoring and quantifying use-related damage on macro lithic tools. For instance, GIS has been used to assess battering marks on both experimental and archeological pounding tools (Arroyo and de la Torre 2016; de la Torre et al. 2013). Specifically, de la Torre et al. (2013) were able, combining use wear results and GIS, to identify damage patterns associated with the exploitation of experimental quartz anvils to break bones, crack acorns, pound meat, and knap stones. Arroyo and de la Torre (2016), instead, combined use wear and GIS to investigate surface modification on archeological pounding tools coming from Beds I and II at Olduvai Gorge, providing relevant insights regarding the use of these implements in Early Stone Age contexts.

In the last few years, several works (Benito-Calvo et al. 2015; Caruana et al. 2014) tested the specific potential of the combination of 3D scanning and GIS in the quantification of battering 
marks on percussive tools. In particular, such methods were used by Benito-Calvo and colleagues (Benito-Calvo et al. 2015) in order to identify and compute the use-related damage on battered tools used by extent primates from Bossou (Guinea). As a result, the author highlighted the potentials of morphometric analysis in the discrimination between damage related to active and passive pounding activities. Caruana et al. (2014) presented the result derived from the use of a spatial recognition algorithm applied to 3D models of battered tools, finalized to identify variation in surface roughness on both experimental and archeological implements. By analyzing morphometric features as surface, volume, perimeter, and area, the authors were able to distinguish between natural and anthropogenic damage patterns. More recently, Benito-Calvo and colleagues (Benito-Calvo et al. 2017) investigated patterns of surface changes on experimental quartzite and basalt battering tools used to break bones. By treating 3D surface measurements obtained through the use of a confocal microscope and processed with GIS software, the authors were able to identify and monitor significant changes in surface topography at a micro scale. The results suggested differences in the degree of modification occurring between active and passive elements used to break bone, with the anvils exhibiting deeper modification while larger surface areas were modified on the hammerstones (Benito-Calvo et al. 2017) More recently, Benito-Calvo and colleagues (Benito-Calvo et al. 2018) evaluated the high potential of the application of $3 \mathrm{D}$ $360^{\circ}$ morphometric analysis in the analysis of pounding tools. Through the direct processing of 3D point clouds, the authors analyzed various morphometric variables on a complete tool, measuring patterns of modification related to the use of stone tools in baobab fruit processing (Adansonia digitate) processing by Hazda foragers in Tanzania (Benito-Calvo et al. 2018). All of the aforementioned studies demonstrated how the application of quantitative approaches (e.g., GIS) in the analysis of stone tool use allows the identification of battered areas and the kinetics involved in the use of pounding tools. However, as already underlined by Arroyo and de la Torre (2016), a reliable interpretation of pounding tools function demands the qualitative data obtained though the microscopic analysis of the surfaces. To this matter, the study of Caricola and colleagues (2018) focused on the use of hammerstones coming from the Paleolithic site of Fumane Cave (Italy) represents a clear example of the combination of use wear analysis, 3D scanning and GIS. Indeed, the authors, through the application of this integrated approach, provided a detailed interpretation of the function and gestures associated with the use of macro tools at the site, stressing the importance of combining quantitative data coming from geomatic techniques with qualitative results achieved through use wear analysis performed at low and high magnifications (Caricola et al. 2018).

Despite the positive results achieved by combining 3D scanning and GIS techniques in the study of the use of pounding tools, the potential of such approach still needs to be fully tested with regard to the analysis of residue distribution. As a matter of fact, investigating spatial distribution of residues in relation to patterns of surface modification would allow one to better understand how activities and gestures in working these materials affect residue disposition on the used tools. As recently stressed by Mercader et al. (2018), by allowing to discern between naturally adhered organic remains (e.g., sediments) and use-related ones, patterns of residue distribution over a tool's surface positively contributes to the debate regarding ancient contamination,

Here, we present experimental data coming from the analysis of an assemblage of modern groundstones systematically utilized to process wild grain grasses, roots, and fruits. Our methodological approach focuses on the combination of 3D scanning performed through close range photogrammetry, spatial analysis, use wear, and micro-residue (namely starch granules) analysis. Such newly combined approach provides the first opportunity to investigate and quantify functional modifications associated with wild plant processing on experimental groundstone surfaces. Further, the analysis of the spatial distribution of residues allowed us to monitor how this relate to the performed gestures and to identify high potential residue sampling areas over a tool's surfaces. This latter aspect represents a new contribution to the analysis of ancient residues on stone tools with high potential to oversee sampling strategies of archeological groundstone. For this reason, even though we focused our analysis on wild plant processing, our results highlight the potential application of this methodological framework in future works focusing on groundstones used in domestic plant processing. In a broader perspective, our work aims to contribute to the ongoing debate in the field of starch research regarding ancient contamination and authentication of starch granules (Crowther et al. 2014; Mercader et al. 2018), providing new means for strengthening the validity of this analysis in the study of ancient human behaviors.

\section{Methodology}

In order to analyze patterns of modifications caused by the use of groundstones for wild plant food processing activities, we elaborated an integrated approach based on the combination of the following: (a) 3D scanning through close range photogrammetry; (b) utilization of a GIS software to investigate patterns of surface modification and distribution of both use wear and starch granules; (c) use wear analysis performed at low and high magnifications; (d) residue analysis; (e) experimental archeology (Fig. 1). Our combined approach allowed us to:

- gather quantitative and qualitative data related to wild plant processing using groundstones; 


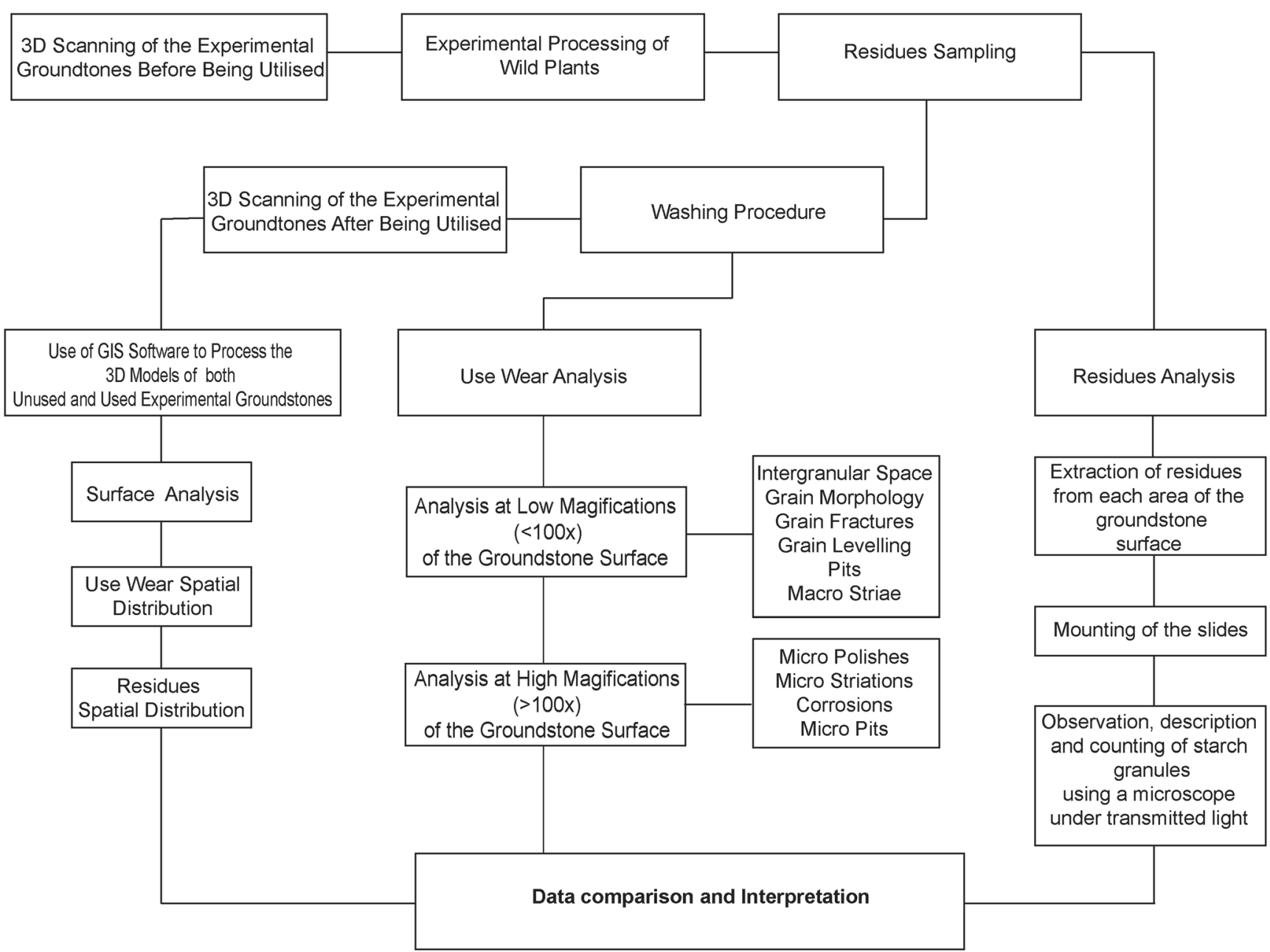

Fig. 1 Flowchart representing the workflow adopted to analyze each of the experimental groundstones

- perform a cross-comparison between the geomatic observations and the direct analysis of the utilized areas of the groundstones at low and high magnifications; and

- map residue distribution patterns across the tool's surface and investigate how they relate to the activity performed (gesture and worked material) and surface topography.

\section{Experimental activity}

The experimental activity, performed by MLC, part of a largescale project (HIDDEN FOODS - ERC StG Project, GA 639286, PI: EC) focused on the exploitation of wild plants by Paleolithic and Mesolithic communities, was aimed to test the functionality of groundstones for processing different parts of wild plant foods, such as grains, roots, and fruits. Plant foods have been processed using grinding stone tools performing both pounding and grinding activities. Pounding involves the contact between the active and passive tools through a series of fast and repeated vertical movements, while during grinding the active tool is in continuous contact with the surface of the passive tool through back and forth, circular, or oblique movements (Adams 2014a; de Beaune 2004; Wright 1992). In terms of results, pounding is aimed to break into small pieces the processed substance, while grinding leads to the pulverization the worked matter (Adams 2014b). Some of the variables recorded included the following: (a) the type of wild plant worked; (b) the state (dry or fresh) of the worked material; (c) the gestures used during the test; and (d) the duration of the experiments. All the experimental groundstones presented in this study are made of very compact and homogeneous sandstones recovered from the Esaro River in South Italy (Fig. 2) (Tables 1 and 2). The mineral composition of the selected sandstone is characterized by a high presence of quartz $(65 \%)$ and in lower percentages by pheldspar, muscovite, biotite, and chlorite, cemented within each other through silica, carbonates, and iron oxides. Overall, the size of the quartz grains is small (ca. $0.25 \mathrm{~mm}$ ), is characterized by a high degree of angularity, and appears densely distributed within the matrix. The overall high homogeneity of the selected raw material allowed us to limit the variables affecting the development of use wear. Moreover, the material's high abrasive 


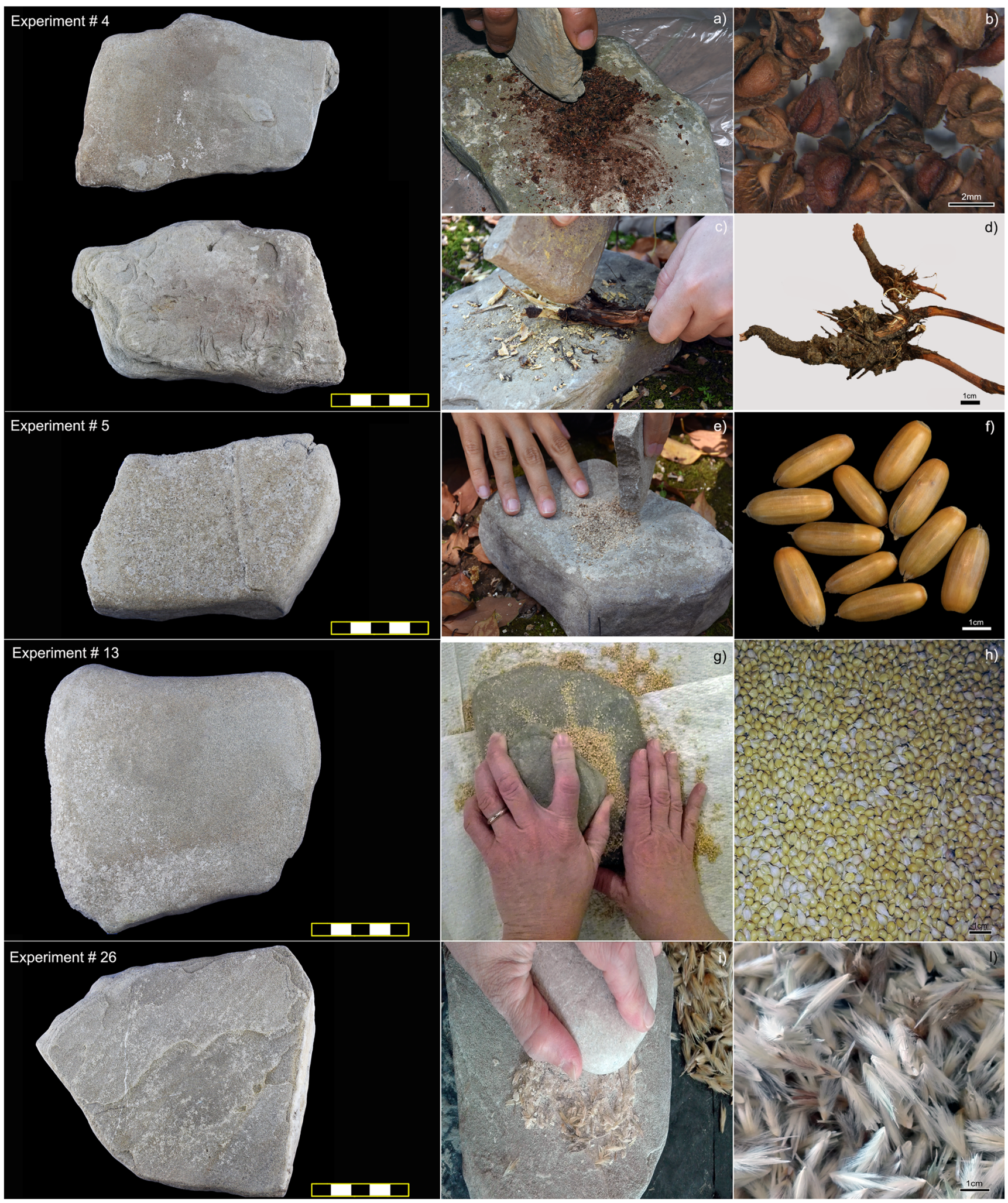

Fig. 2 Experimental groundstones used for processing a, b Rumex crispus fruits, c, $\mathbf{d}$ Rumex crispus roots, e, $\mathbf{f}$ Quercus pubescens, $\mathbf{g}, \mathbf{h}$ Setaria italica, and $\mathbf{i}, \mathbf{l}$ Avena sterilis

qualities made it distinctly functional in particular during grinding activities. Regarding the species of plants processed, acorns (Quercus pubescens), oats (Avena sterilis), curly dock (Rumex crispus), and foxtail millets (Setaria italica) have been selected for our experiments due two main reasons. First, the selection of these specific plant species is given in light of the aims of the 


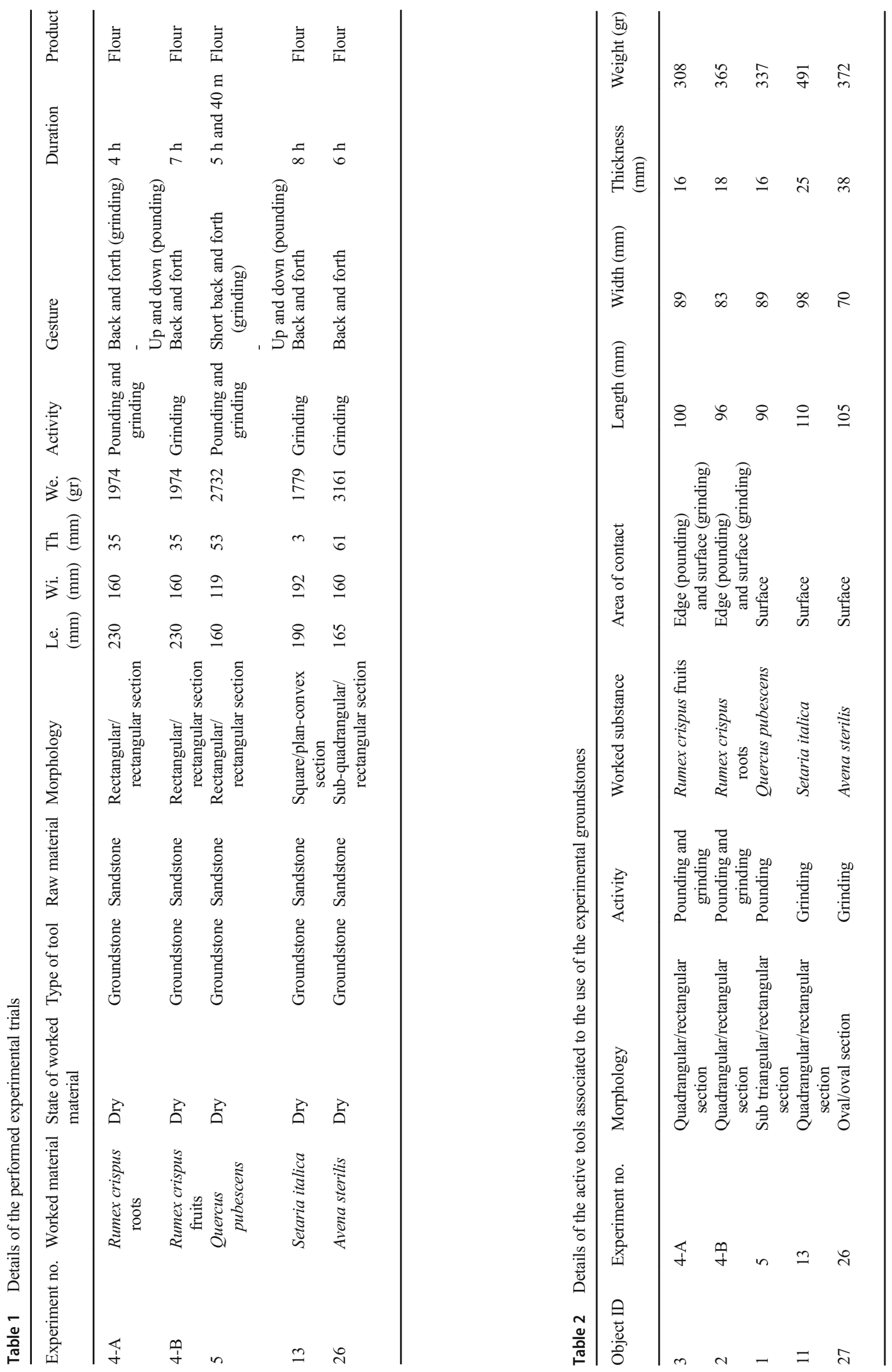


Table 3 Details of the experimental groundstones $3 \mathrm{D}$ models

\begin{tabular}{lllll}
\hline Experiment no. & Pictures per face & $\begin{array}{l}\text { Dense cloud } \\
\text { points }(n)\end{array}$ & Mesh (faces/vertices) & $\begin{array}{l}\text { DEM resolution } \\
(\mathrm{mm} / \text { pixel })\end{array}$ \\
\hline $4-\mathrm{A}$ & 72 & $9,250,237$ & $1,850,046 / 925,051$ & 0.1 \\
$4-\mathrm{B}$ & 72 & $8,697,885$ & $1,739,575 / 869,790$ & 0.1 \\
5 & 72 & $12,928,186$ & $2,585,636 / 1,292,820$ & 0.1 \\
13 & 72 & $10,004,755$ & $2,000,951 / 1,000,465$ & 0.09 \\
26 & 72 & $10,240,909$ & $2,048,280 / 1,024,040$ & 0.1 \\
\hline
\end{tabular}

Hidden Foods Project, aiming to reconstruct the role and consumption of plant foods during the Paleolithic and the Mesolithic. Secondly, a wild range of studies documented the consumption and use of these plant species Paleolithic and Mesolithic contexts of South Eastern Europe, which represents the geographical frame on which the HIDDEN FOODS - ERC

Table 4 Count and dimensions of residues observed on the groundstone surface of each experiment. Note that the dimensions are referred only to intact starch specimens and compounds

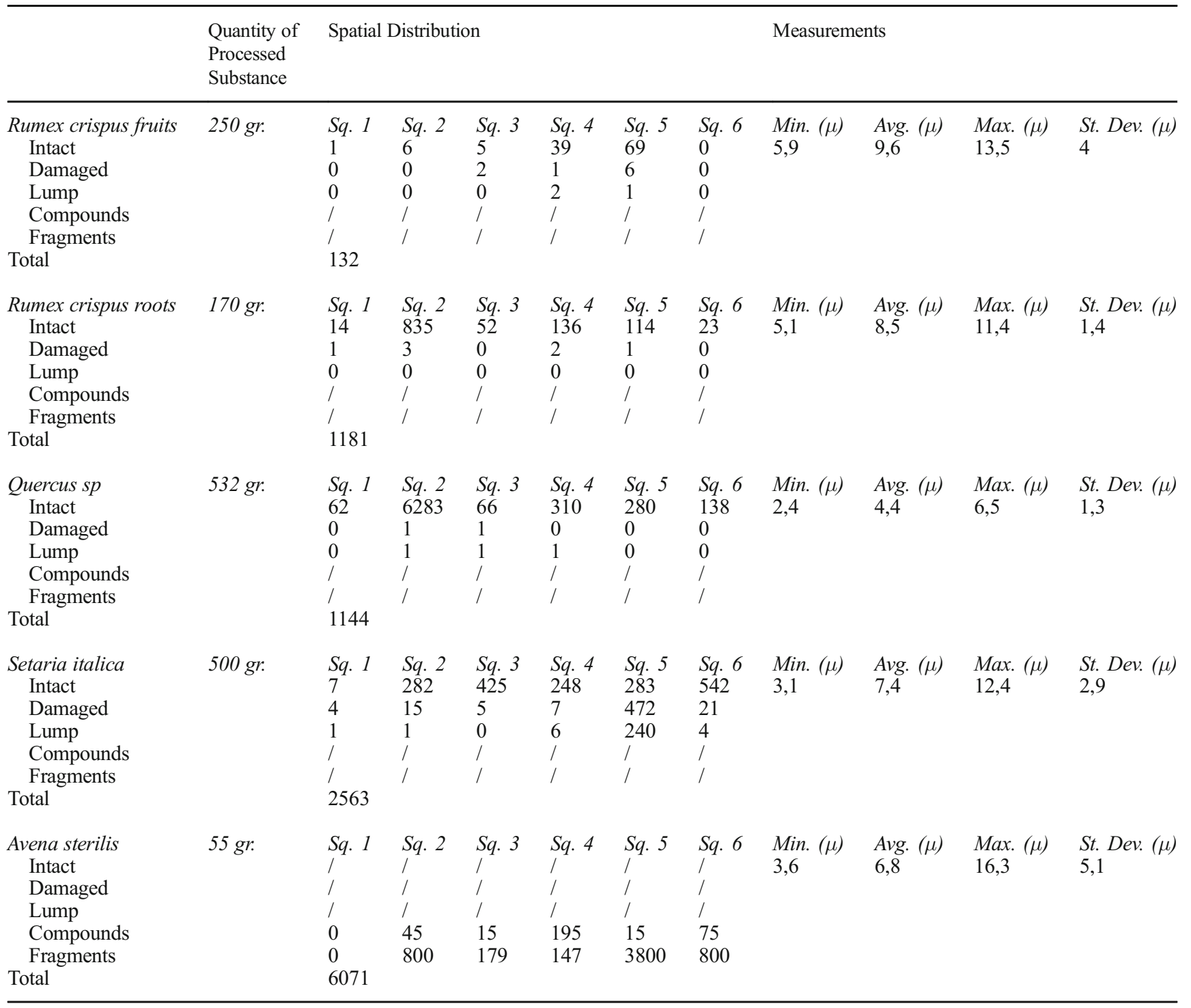


Table 5 Main morphological attributes of the identified starch granules

\begin{tabular}{|c|c|c|c|c|c|c|c|}
\hline Plant species & $\begin{array}{l}\text { Average } \\
\text { size }(\mu \mathrm{m})\end{array}$ & Shape (2D) & Shape (3D) & Hilum morphology & Lamellae & $\begin{array}{l}\text { Extinction } \\
\text { cross }\end{array}$ & Birefringency \\
\hline Rumex crispus fruits & 8 & Polygonal & Polygonal & Centric and depressed & l & l & Medium \\
\hline Rumex crispus roots & 18 & $\begin{array}{l}\text { Lenticular/plano } \\
\text { convex }\end{array}$ & Lenticular & Centric and depressed & l & $\begin{array}{l}\text { Elongated } \\
\text { with arms }\end{array}$ & Medium \\
\hline Quercus pubescens & 15 & Kidney/sub-oval & Oval & $\begin{array}{l}\text { Centric with a long } \\
\text { fissure }\end{array}$ & Rare & Visible & Strong \\
\hline Setaria italica & 7 & Globular & Polygonal & Centric with vacuole & l & Visible & Strong \\
\hline Avena sterilis & 15 & Polyhedral/irregular & Polyhedral/irregular & Not visible & / & Visible & Medium \\
\hline
\end{tabular}

StG Project focuses its research (Cristiani et al. 2016; Lippi et al. 2015; Marinova et al. 2013). Rumex crispus fruits (exp. no. 4 Surface-A, Fig. 2a) were processed for $7 \mathrm{~h}$. The dry fruits were ground through resting percussion consisting of back and forth movements. The amount of worked material remained almost unchanged once the experiment was completed (from 250 to $240 \mathrm{~g})$.

Rumex crispus roots (exp. no. 4 Surface-B, Fig. 2b) were processed for $4 \mathrm{~h}$. The first phase of the experiment was devoted to crushing roots through pounding. Once crushed through pounding, roots were ground using a resting percussion and back and forth movements. The amount of worked material decreased from 170 to $120 \mathrm{~g}$ once the experiment was completed.

Quercus pubescens acorns (exp. no. 5, Fig. 2c) were processed for $5 \mathrm{~h}$ and $40 \mathrm{~min}$. Acorns were first crushed and then ground in order to obtain flour. Crushing was performed through pounding while back and forth movements were applied to produce flour. The amount of worked material decreased from 532 to $300 \mathrm{~g}$ once the experiment was completed.

Setaria italica grains (exp. no.13, Fig. 2d) were processed for $8 \mathrm{~h}$. Dry grains were ground according to a resting percussion activity applied with back and forth movements. The amount of worked material decreased from 500 to $300 \mathrm{~g}$ once the experiment was completed also due to the previous phase of glumes cleaning.

Avena sterilis grains (exp. no. 26, Fig. 2e) were processed for $6 \mathrm{~h}$. Grinding using back and forth movements was performed in order to process the grains without glumes. As experienced during experiment n. 13, the amount of worked material decreased significantly from 55 to $25 \mathrm{~g}$ once the experiment was completed. Such a change in the amount of worked material is explained by the fact that wild oats glumes are particularly fibrous and heavy.

\section{D modeling}

Lately, 3D artifact documentation aimed at analytical and outreach purposes has become a common practice in archeology.
Two main acquisition techniques can be adopted for the creation of 3D models: 3D scanners or close-range photogrammetry (CRP). 3D scanners work with a source of light, laser (laser scanner), or patterns of white light (structured light scanner), hitting the object and a camera capturing the form in which light is deformed. CRP is based upon the gathering of reference points on digital images shot from multiple angles.

The relative position in 3D space of the points is then determined through triangulation (Luhmann et al. 2013; Porter et al. 2016). Both techniques give the possibility to produce highresolution 3D models, which can be used in geometric morphometric analysis of stone tools (Bretzke and Conard 2012; Chacòn et al. 2016; Grosman et al. 2008; Morales et al. 2015), percussion tools (e.g., Caruana et al. 2014; BenitoCalvo et al. 2015), and cutmarks on bone surfaces (Arriaza et al. 2017; Maté-González et al. 2018; Maté-González et al. 2017). For the purpose of this study, we adopted the photogrammetric technique, following the methodological framework proposed by Porter et al. (2016) to produce accurate 3D models of the experimental groundstones before and after use. Pictures were taken utilizing a Nikon D7200 DSLR equipped with a Nikkor Lens AF-S VR 105-mm lens. The objects were placed over an automated turntable (Foldio 360) and pictures were automatically shot. A whole revolution comprised 24 shots, one every $15^{\circ}$. Pictures were taken at three different height stages (every $10 \mathrm{~cm}$ starting at object level) and the camera was raised every time the object completed a full $360^{\circ}$ rotation. After these three steps, the object was flipped over and pictures of the opposite face were taken from the highest to the lower height. A total of 72 pictures were taken for each face of the groundstone resulting in the total of 144 pictures per object.

The sets of images were processed using Agisoft Photoscan Pro v.1.4.2 software. Pictures of each face of the groundstones were aligned and high definition dense clouds were generated. The two dense clouds were then aligned and merged thus creating a complete model of the object which was then properly scaled. Finally, a mesh originating from the merged dense cloud was generated. Once created, the 3D models of the groundstones were 
used to build digital elevation models (henceforth DEMs) of each of the surfaces. DEMs (with resolution ranging between 0.098 and $0.1 \mathrm{~mm} / \mathrm{px}$ ) (Table 3) were created from the dense point clouds of each surface using a planar projection based on four markers placed over the tool's surface and exported as raster images in GeoTIFF format.

\section{Use wear analysis}

Traces generated by the use of groundstones in plant processing have been analyzed applying both low- and high-power approaches (Adams 2014a, b; Bofill et al. 2013; Dubreuil et al. 2015; Dubreuil and Savage 2014; Hamon 2008; Hayes 2015; Keeley 1980; Tringham et al. 1974; Van Gijn 2010). The observation of groundstone at low and high magnifications allows to analyze patterns of surface modification at both a macro (e.g., macro- and micro-topography; intergranular space; grains; striations and pits morphology) and micro scale (e.g., polishes; abrasions and micro striations) (Conte et al. 2015; Dubreuil et al. 2015; Hayes et al. 2017, 2018; Van Gijn 2010). By combining the analysis of macro and micro wear identified over a tool's surfaces, it is possible to isolate features associated with the worked material and its state (e.g., dry, wet) as well as to the specific gestures (e.g., thrusting and resting percussion; circular or back and for the movements) applied during its processing.

Macro wear present on the experimental groundstone sample subject of this study has been analyzed using a Zeiss AxioZoom V16 motorized stereomicroscope, with magnifications up to $178 \times$. Micro wear were analyzed using a Zeiss AxioScope metallographic microscope with magnifications from $100 \times$ to $400 \times$. In order to observe the groundstone surface at higher magnifications, silicon casts were made of the utilized areas using Provil Novo Light Fast ${ }^{\circledR}$ (Banks and Kay 2003; Hayes et al. 2018; Macdonald et al. 2018; Pedergnana and Ollé 2017). Before being observed under the microscope, groundstones have been washed by hand in hot demineralized water utilizing a $2 \%$ neutral phosphate-free detergent (Derquim®) and subsequently rinsed in fresh demineralized water (Pedergnana and Ollé, 2017).

\section{Starch analysis}

Once the experimental trials were completed, the artifacts were sampled for starch analyses. In order to avoid contamination between different experiments, powder-free gloves were worn all the time, laboratory surfaces were cleaned using hot water and neutral soap, and a plastic film was applied to the table surface used where the groundstone was prepared for sampling.
The active surface of each artifact was divided in six squares, numbered from 1 to 3 (upper line) and 4 to 6 (lower line), and the number of starch granules present in each square was counted (Table 4).

Since the purpose of the analysis was to monitor the distribution of the starch granules on the surface, the distribution of plant macro residues (e.g., fibers, flour.) on the tool surfaces was only described qualitatively (localization and distribution manner) with the naked eye. Starch have been extracted and analyzed following criteria known and widely accepted by modern and ancient starch analysts (Atchison and Fullagar 1998; Barton and Torrence 2015; Field et al. 2009; Fullagar et al. 2008; Haslam 2006; Henry et al. 2009; Loy et al. 1992; Mercader et al. 2018; Torrence and Barton 2016; Yang and Perry 2013). We stress that the origin of the starch granules was known to us, and the scope of this work is to assess where larger masses of starch granules gather on the stone surface and assess where they appear more damaged. A more detailed work on starch granule morphology from species and their potential to be identified in archeological record has being carried out.

Sampling was performed by placing $20 \mu \mathrm{l}$ droplet of ultra-pure water with a micropipette on the selected spots. The drops were left $1 \mathrm{~min}$ on the artifact in order to soften the residues and then carefully agitated with the pipette tip before being pipetted out. Samples were then placed on a slide and mounted with a $50 \%$ solution of purified water and glycerol. The observation was performed using a Zeiss Axio Imager M2 compound microscope equipped with the magnification of up to $630 \times$. Considering the predictable high number of starch granules present on each experimental artifact, the count was made on a $15 \times 15-\mathrm{mm}$ spot placed in the middle of the slide. In the case of Avena sterilis, given the high amount compound fragments, we counted the number of fragments within $1 \times 1 \mathrm{~mm}$ within the $15 \times 15-\mathrm{mm}$ transect and multiplied it by the area of the transect $\left(225 \mathrm{~mm}^{2}\right)$. The presence of starch granules was recorded according to their specific features (bimodal type, presence/absence of lumps), their preservation (complete or damaged), and distribution (single or compound). Lumps were also recorded in term of size in order to reconstruct the number of granules stored in each of it, according to the average size of a single grain of the analyzed species. Experimental starch description was based on the geometric morphometric typology of the grains (Mercader et al. 2018), position and form of the hilum, presence and appearance of surface features, depressions, fissures, presence of lamellae and extinction cross, birefringency, and specific distribution (e.g., bimodal distribution, presence/ absence of lumps) ( Haslam 2004; Horrocks et al. 2004; Piperno et al. 2000) (Table 5). 
Besides the counting of the starch granules, we also took pictures of the transects we analyzed to provide a representative view of the density of such granules in the analyzed samples. Some of such difference were striking, and the representative pictures will support the visualization of the data.

\section{Spatial analysis of the surface}

In order to monitor changes in surface topography related to the processing of wild plants, the DEMs of groundstones before and after use were analyzed using a GIS software. The raster DEMs created in Agisoft Photoscan Pro were imported in the open source GIS software QGis (v.3) (https://www.qgis.org/en/site/).

The software was used to investigate modification in the surface topography through the creation of digital surface models (DSMs) (Benito-Calvo et al. 2015). As demonstrated by Benito-Calvo et al. (2015, 2017, 2018), slope and surface roughness analysis provides useful insights concerning the pattern of modification of stone tool surfaces. For the purpose of our study, these were generated using the GDALdem (http://www.gdal. org/gdaldem.html) package available in QGis. Slope identifies the rate of change in the $z$ value from each of the cells composing a raster surface and allows identifying changes in surface elevation as depressions, pits, or leveled areas which can originate by tool use. Surface Roughness analyzes the degree of irregularity characterizing a given surface. Roughness values are calculated by the largest inter-cell difference of a central pixel and its neighboring cells. The creation of these specific DSMs of the groundstone surfaces before and after their use allows monitoring patterns of surface changes, providing a visual aid through the mapping of changes in the elevation and surface variability, and allowing to quantify the amount of modification.

\section{Starch granule spatial distribution}

As for the surface analysis, GIS was used in order to investigate the spatial distribution of starch granules left from wild plant processing over the groundstone surface. Each of the surfaces was divided into $3 \times 3-\mathrm{cm}$ grid system automatically generated and then adapted to the groundstone outline, mimicking the areas where starch sampling was actually performed. Within these areas, random points, with a fixed distance of $1 \mathrm{~mm}$ between each point, were generated. Different sets of random points were created for (a) intact starches, (b) damaged starches, (c) lumps, (d) compounds, and (e) fragmentary starch granules. The number of points corresponded to the number of residue unities observed by the analyst over each of the six slides corresponding to the equivalent surface area. Starch grain density over the groundstone surface was analyzed by creating heatmaps. Heatmap radius was fixed to $0.05 \mathrm{~cm}$ while the pixel size was set to $0.01 \mathrm{~cm}$.

Heatmaps were generated only for intact starch granules and compounds for three main reasons:

1) Intact starch granules are much more relevant in terms of species identification than damaged ones.

2) Overall, exception made for exp. 13 (Setaria italica), the number of damaged starch granules and lumps are too low to compute accurate and reliable distribution maps.

3) In the case of wild oat (exp. 26), the number of fragments across the surface is too high and their distribution over the groundstone surface does not provide any useful information in terms of their interpretation. This is probably due to the breaking up of compound granules that characterize the genus Avena, among others.

\section{Results}

\section{Experiment no. 4-A—curly dock (Rumex crispus) fruits}

\section{Surface morphometric analysis}

The surface of the tool has been utilized to process fruits of curly dock through grinding activity. Before its use, the surfaces was characterized by the predominance of low slopes a with mean value of $9.4^{\circ}$, with occasional steeper slopes of $25.2^{\circ}$ localized over the right-hand side of the groundstone (Fig. 3a).

After being used, an overall decrease in the mean slope value $\left(9.4^{\circ}\right.$ to $\left.8.5^{\circ}\right)$ was recorded. The steeper slopes present on the right-hand side of the surface appeared leveled by the back and forth gestures performed while grinding fruits. Moreover, an area of low slopes, not present before the use of the groundstone, developed over the top left portion of the surface. This corresponds to the portion of the surface utilized to pound the fruits during the experiment (Fig. 3b).

In regard to surface roughness, before being used, the groundstone surface appears homogeneous overall (Fig. 3c), with a mean roughness value of 0.00006 . The grinding of curly dock fruits led to an increase in the overall degree of homogeneity of the surface, where a 

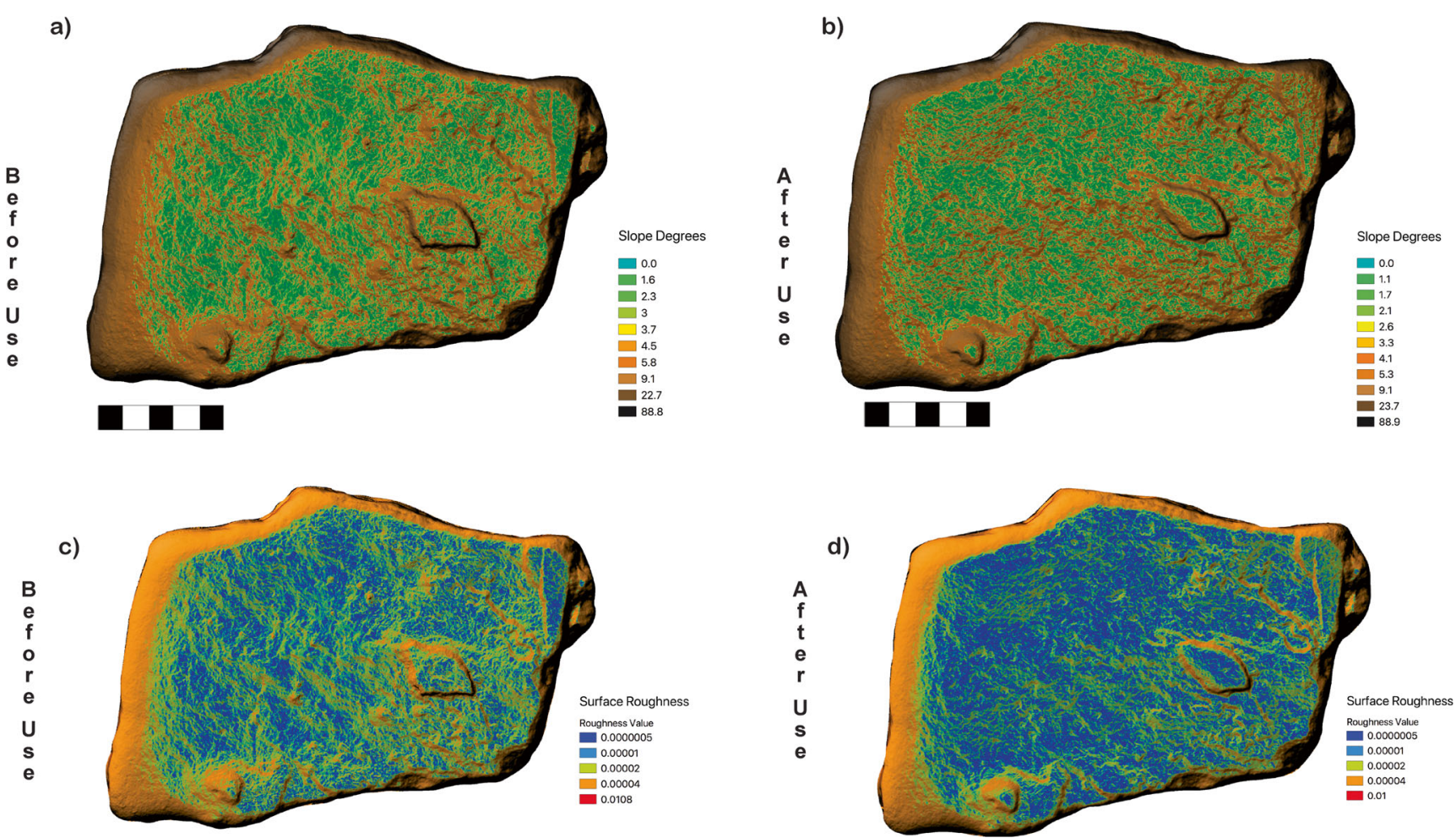

Fig. 3 DSMs of the slopes $(\mathbf{a}, \mathbf{b})$ and roughness $(\mathbf{c}, \mathbf{d})$ identified on the surface of experiment 4-A utilized to process Rumex crispus fruits before (a, c) and $\operatorname{after}(\mathbf{b}, \mathbf{d})$ use

mean roughness value of 0.000059 was recorded (Fig. 3d). The lower roughness areas are small in dimensions (mean area $0.5 \mathrm{~cm}^{2}$ ) and well spread across the surface as indicated by the density value at $0.28 \mathrm{~cm}^{2}$.
Observed at higher magnifications $(50 \times-70 \times)$ the surface area exhibiting the lowest value of roughness appear leveled, and oriented micro-polishes, characterized by a covered-connected distribution are visible on the top of
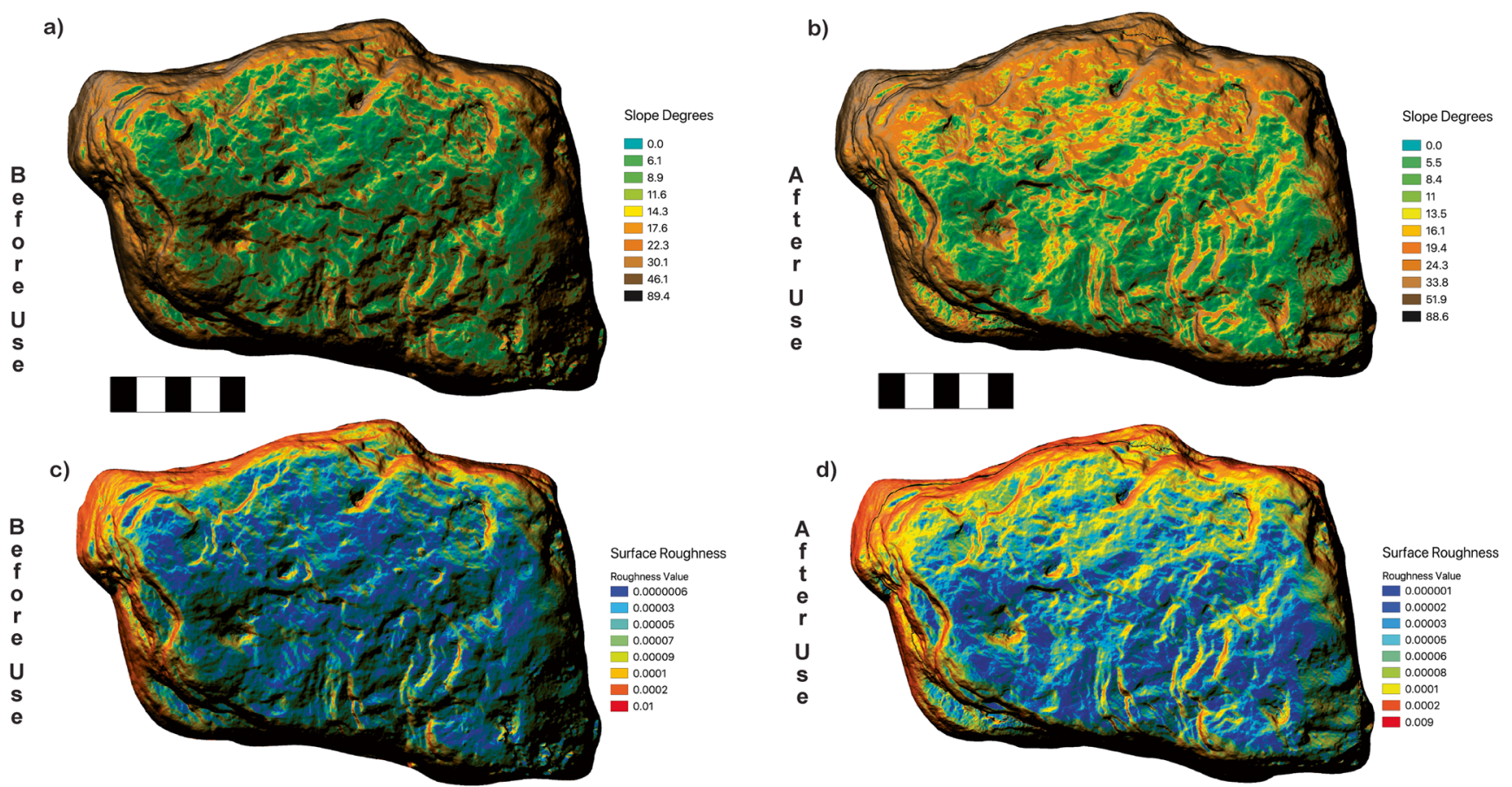

Fig. 4 DSMs of the slopes $(\mathbf{a}, \mathbf{b})$ and roughness $(\mathbf{c}, \mathbf{d})$ identified on the surfaces of experiment 4-B utilized to process Rumex crispus roots before (a, c) and after (b, d) use 
the grains (Fig. 5c). At $200 \times$ magnifications, the identified polishes exhibit a smooth texture and a domed topography along with the presence of micro-pits. Long, superficial striations are also present, mimicking the same orientation pattern of the polished areas (Fig. 5d).

\section{Residue spatial analysis}

With the naked eye, macro residues are widely and finely distributed over the surface. The overall number of identified starches over the groundstone surface was low (n. 132). The majority of the starches were intact (n. 120), while few damaged starches (n. 9) and lumps (n. 3) were observed. The areas of maximum concentration of the starches corresponded to squares 4 and 5 of the groundstone surface, which can be defined as peripheral to the portion of surface mostly utilized for the grinding Rumex crispus fruits. Indeed, this latter included squares 1,2 , and 3 , where only few complete (n. 12) and damaged (n. 2) starches were found (Fig. 6a, b).

\section{Experiment no. 4-B—curly dock (Rumex crispus) roots}

At its natural state, the surface of the groundstone is characterized by intermediate slopes bearing a mean value of $21.7^{\circ}$ (Fig. 4a). Steeper slopes are preset as well across the surface, bearing a mean value of $48.1^{\circ}$. In regard to surface roughness, a variable topography characterizes the surface of the groundstone at its natural exhibiting a mean roughness value of 0.00016 (Fig. 4c).

After use, the slope mean value increased from its initial one $\left(21.7^{\circ}\right.$ to $\left.22.2^{\circ}\right)$. The pounding of the roots led to the development of intermediate slopes $\left(24.3^{\circ}\right)$ over the upper area of the surface, while slopes ranging between $5.7^{\circ}$ and $10.9^{\circ}$ were recorded before its use. On the other hand, the lower area of the surface, utilized for root grinding, suffered an overall smoothing
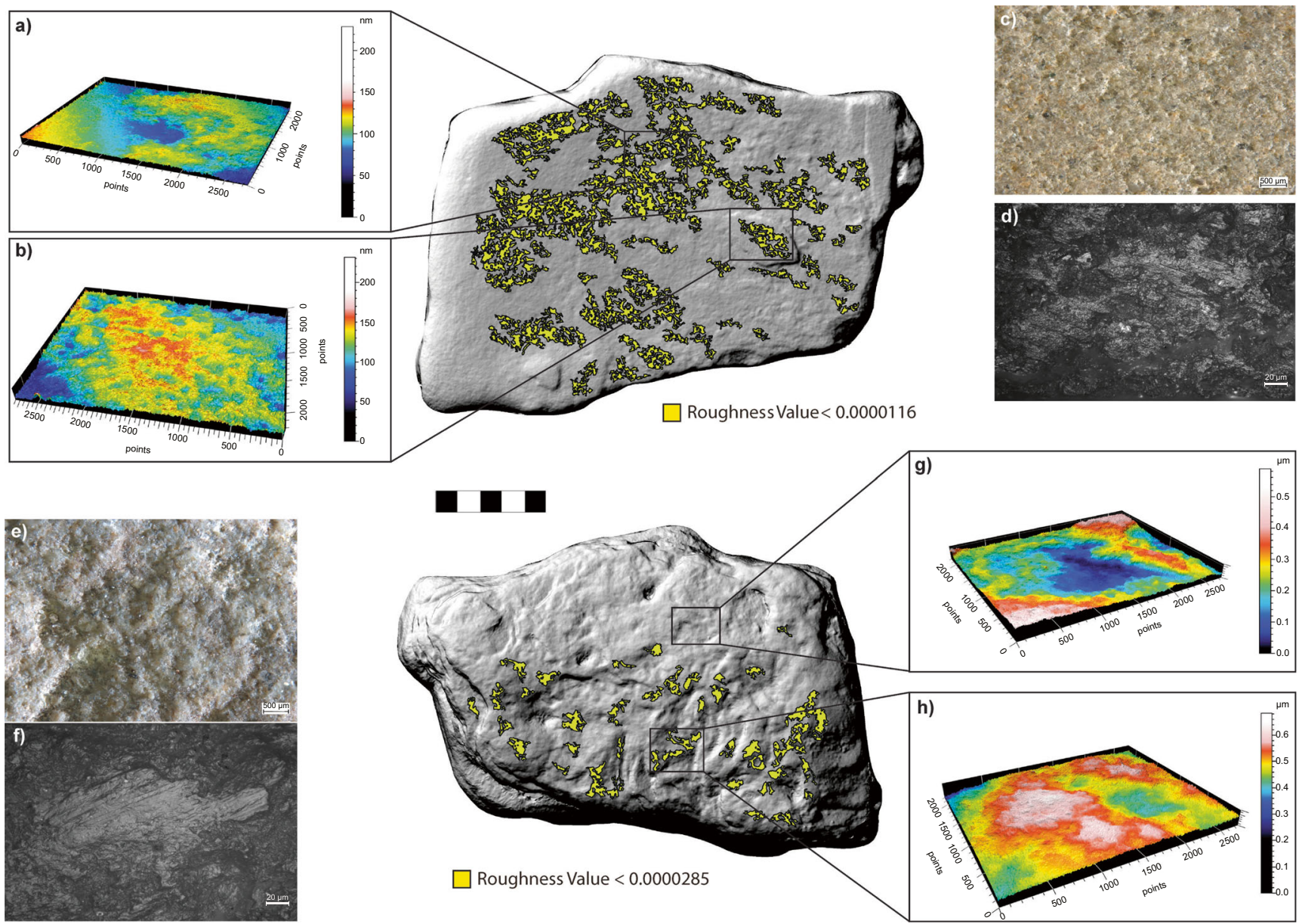

Fig. 5 Low roughness areas bigger the $10 \mathrm{~mm}^{2}$ developed after the use of the groundstone. $\mathbf{a}, \mathbf{b}$ and $\mathbf{g}, \mathbf{h}$ 3D rendering of the low roughness surface areas observed at $\times 50 ; \mathbf{c}, \mathbf{d}$ and $\mathbf{e}, \mathbf{f}$ Use wear identified over the low roughness areas observed at magnifications ranging from $\times 50$ to $\times 200$ 


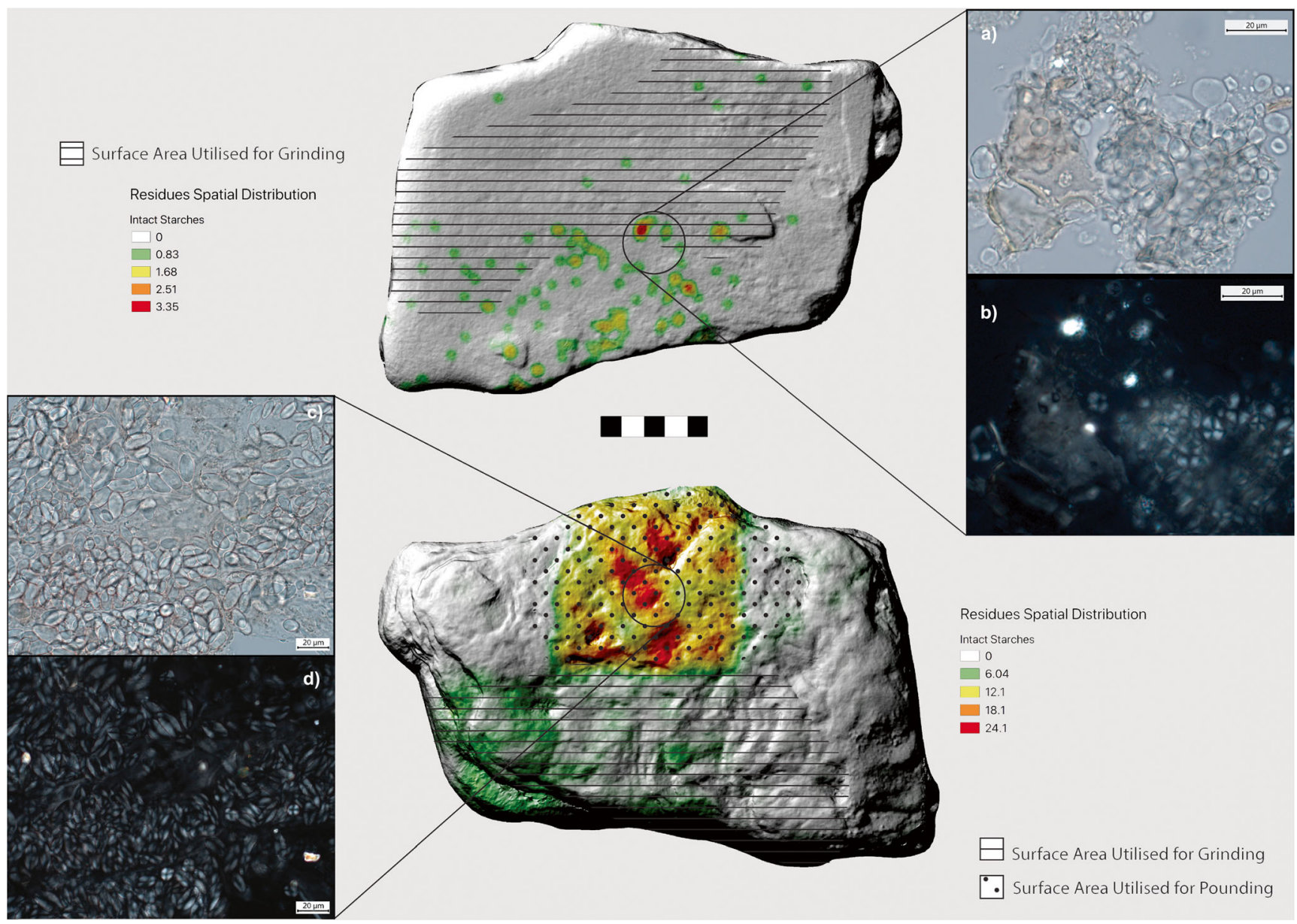

Fig. 6 Residue distribution across the two surfaces of the groundstone utilized to process curly dock (Rumex crispus) fruits and roots. a, b Granules with suboval/subtriangular in 2D, longitudinal fissure associated to curly dock root processing by pounding. Notice the preservation of an almost intact amyloplast cell with starch granules still lodged in it. $\mathbf{c}, \mathbf{d}$ Polyhedral starch granules characterized by a central depressed hilum and no lamellae associated to curly dock fruit grinding. Notice the presence of intact, damaged starches as well as lumps of granules characterized by the disappearance of the lower slopes $\left(<24.2^{\circ}\right)$, and the leveling of the higher ones (Fig. $4 \mathrm{~b}$ ).

After being used, the surface is characterized by an increase in its homogeneity (mean roughness value 0.00015) (Fig. 4d). The top area of the surface resulted more heterogeneous than the lower one. Here, indeed, low roughness areas are rare, and when observed at high magnifications, use-related micro-pits are visible, while no diagnostic polish was identified. On the contrary, the lower portion of the surface resulted more homogeneous, characterized by medium-sized (mean area $0.3 \mathrm{~cm}^{2}$ ) low roughness areas rarely connected within each other and dispersed across the utilized surface of the groundstone (density $0.15 \mathrm{~cm}^{2}$ ). At high magnifications, only the upper portions of the grains appeared leveled, and smooth flat polishes, bearing a spot-like distribution, are visible, often associated to long micro striations (Fig. 5e, f).

\section{Residue spatial analysis}

With the naked eye, macro residues are packed over the upper portion of the groundstone surface. On Surface-B, a total of 1181 units between intact and damaged starch granules were identified. The count of undamaged starches sums up to 1174 units, with the higher number of granules (n. 835) identified in square 2 . This area of the surface was mostly utilized to pound Rumex crispus roots. Over the lower portion of the groundstone surface, which was primarily exploited to grind the pounded roots (squares 4,5 , and 6), a smaller amount of intact starch granules was observed (Fig. 6c, d). 

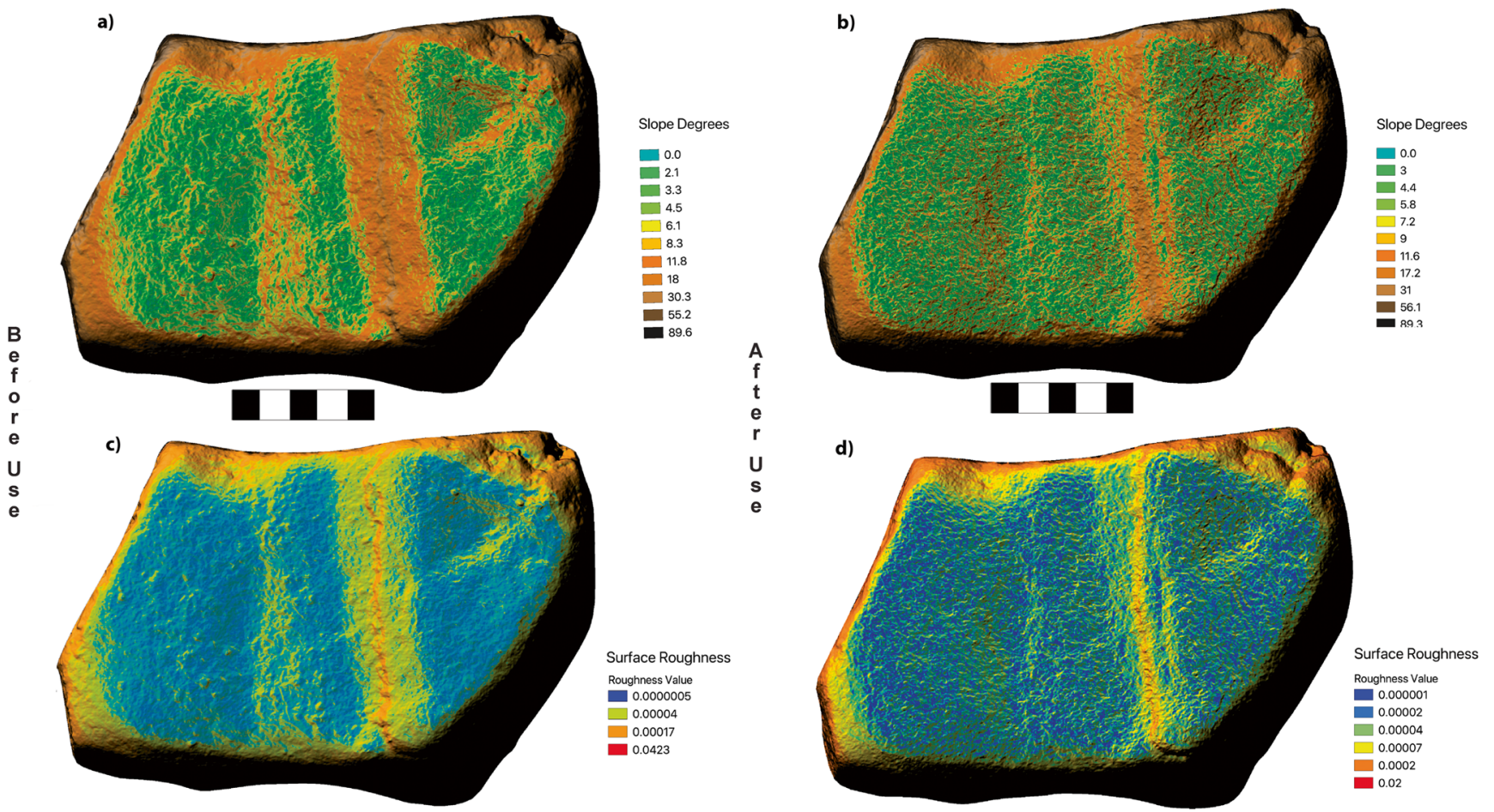

Fig. 7 DSMs showing the variation in slope and surface roughness before and after the use of the groundstone to process acorn acorns

\section{Experiment no. 5-downy oak (Quercus pubescens)}

\section{Surface morphometric analysis}

One face of the groundstone was used during the experiment. At first, the acorns were pounded and subsequently ground, utilizing two different areas of the surface. At its natural state, the groundstone surface topography is characterized by low slopes (mean $18.1^{\circ}$ ). A scarp $\left(55.2^{\circ}\right)$ is present, running across the surface with a North-South direction. On the top right-hand corner of the surface, a small natural depression is present, which has proved its usefulness during the experiment for holding the acorns to be crushed (Fig. 7a). After being used, a slight increase in the mean slope value was recorded (from $18.1^{\circ}$ to $18.6^{\circ}$ ). After its use as a base to process acorns, new low slopes ranging between $11.6^{\circ}$ and $17.2^{\circ}$ developed across the surface in particular over the right side. Moreover, the natural scarp present on the surface left portion resulted to be less steep $\left(31^{\circ}\right)$, and the low slopes surrounding it before the use became heavily leveled or disappeared completely (Fig. 7b). This latter phenomenon was caused by the grinding activity, which was performed over this area of the groundstone surface.
The topography of the groundstone at its natural state is homogeneous overall, exhibiting a mean roughness value of 0.0002 (Fig. 7c). The higher roughness values (> 0.000852 ) were recorded in proximity of the natural scarp running across the surface. After being used, the overall degree of homogeneity remained very similar to its natural one, decreasing from 0.0002 to 0.00019 (Fig. 7d). Although the difference in roughness values was minimal, two phenomena can be recognized through the analysis of the pre and post use roughness DSMs of the groundstone. The values characterizing the natural scarp were lower than the ones recorded before the experiment, ranging between 0.000139 and 0.000346 . However, this decrease in the higher roughness values was compensated by the development of new heterogeneous areas especially in the portion of the surface utilized to crush acorns and localized over the upper-right corner and the left-hand side of the groundstone. Overall, low roughness areas were very small (mean area $0.002 \mathrm{~cm}^{2}$ ) and densely distributed $\left(1.5 \mathrm{~cm}^{2}\right)$ across the groundstone surface. At high magnifications, the utilized areas of the groundstone exhibited deep macro and micro-fractures (Fig. 8c), which were visible over the grains' surfaces. Spots of smooth domed polish (Fig. 8d) were also present over the grains and often associated with long deep micro striations. 


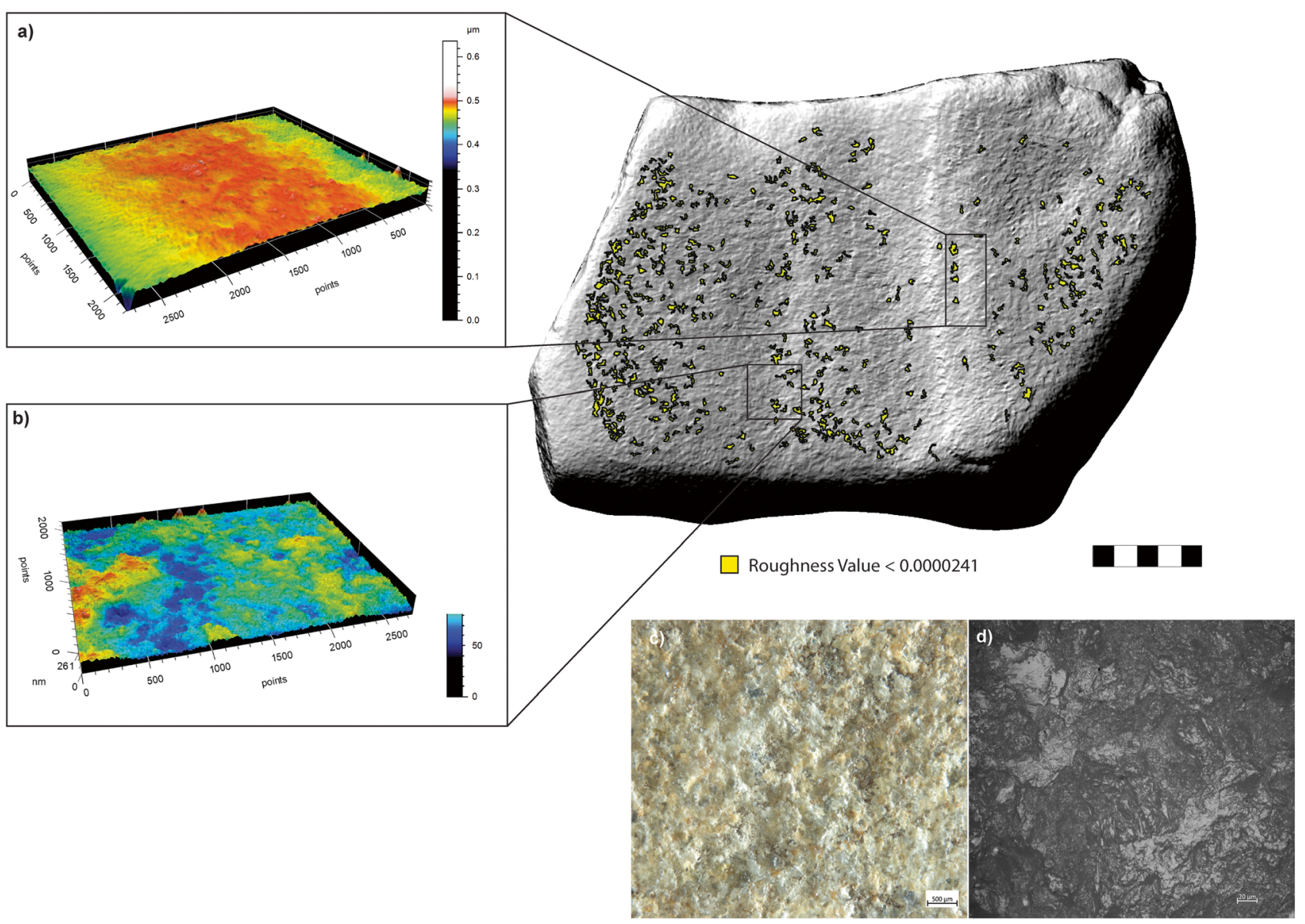

Fig. 8 Low roughness areas bearing an area of more than $10 \mathrm{~mm}^{2}$. a, b 3D rendering of the low roughness surface areas observed at 50x; c, $\mathbf{d}$ use wear identified through the observation of the low roughness areas at $80 \mathrm{x}$ and $200 \mathrm{x}$

\section{Residue spatial distribution}

With the naked eye, macro residues are packed over the center of the surface ad towards the upper-right natural depression preset over the surface. A total of 1144 starches have been identified over the sampled areas of the groundstone surface. Most of the specimens recorded were intact (n. 1139) while only few damaged starches (n. 2) and lumps (n. 3) were identified. Starches were well spread over most of the surfaces, with high concentrations of intact granules located both in the areas where pounding (squares 3 and 4) and grinding (squares 2 and 5) activities were performed (Fig. 9). Spatial distribution maps show a difference in the amount of identified starches within the two areas of the surface utilized to crush acorns. In particular, the depression on the low left corner of the groundstone yielded a higher amount of starches than the one localized on the right portion of the tool's surface. This variation is rather due to a lower number of acorns being processed in this latter area of the surface if compared to the former one than to a difference in the gesture performed.

\section{Experiment no.13-foxtail millet (Setaria italica)}

\section{Surface morphometric analysis}

The surface of the groundstone was utilized to process Setaria italica grains through grinding and pounding. At its natural state, the surface is characterized by low slopes (mean $16.6^{\circ}$ ). Over the left-hand side, the surface exhibits a natural protrusion characterized by the presence of slope concentrations ranging between $17^{\circ}$ and $40^{\circ}$ (Fig. 10a). A similar accumulation is visible as well on the right portion of the groundstone surface (Fig. 10). These topographic irregularities correspond to areas of the groundstone where the surface experienced a natural exfoliation of its uppermost layers. 


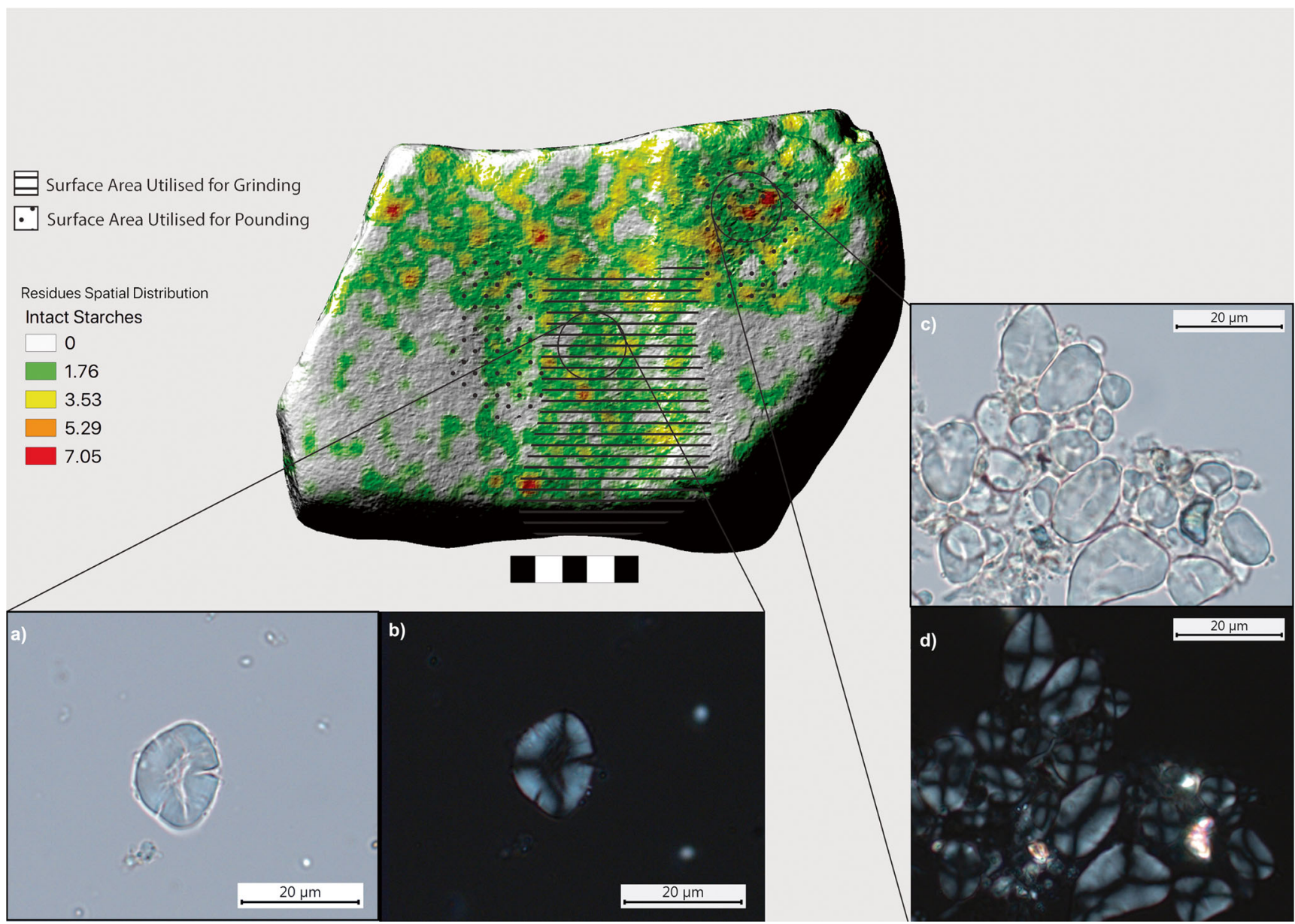

Fig. 9 Residue distribution over the groundstone utilized to process acorn acorns of downy oak (Quercus pubescens). a, b Damaged, isolated oval starch with central fissure. The extinction cross and birefringence are still clear in polarized light. c, $\mathbf{d}$ Group of simple suboval/subtriangular starch grains with centric hilum, visible fissure and strong birefringency in polarized light
After being utilized, a decrease in the mean slope value was recorded, from $16.6^{\circ}$ to $15.3^{\circ}$ (Fig. 10b). The slope concentrations previously identified disappeared, and an intense leveling of certain areas of surface $\left(<2.6^{\circ}\right)$ was visible. This phenomenon was observed especially over the uppermost portion of the natural protrusion, which was the most exploited surface area during the grinding activity. Some degree of modification was also observed over the area just on the right of the protuberance. Here, newly formed flat surface areas were visible along with intermediate slopes. These latter areas developed in correspondence to the point of contact between the lower portion of the surface and the natural protrusion. The development of new topographic features can be explained by a continuous contact between the handstone and the right side of the protrusion, during the grinding activity.

At its natural state, surface topography is homogenous (mean roughness value 0.0001 ), with small heterogeneous areas scattered across the surface (Fig. 10c). After use, a decrease in the mean roughness value was recorded from 0.0001 to 0.00009 (Fig. 10d). Small (mean area $0.027 \mathrm{~cm}^{2}$ ) low roughness areas developed, densely distributed $\left(0.7 \mathrm{~cm}^{2}\right)$ over the uppermost area of the natural protrusion and the area below it (Fig. 11). At high magnifications, in correspondence of the identified low roughness areas, the groundstone surface appeared leveled (Fig. 11c). Smooth polishes exhibiting a flat and cratered topography developed over the top of the grains, often associated with long deep striations (Fig. 11d).

\section{Residue spatial distribution}

With the naked eye, macro residues are widely and homogeneously dispersed across the groundstone surface. A total of 2563 starches comprising intact, damaged specimens and lumps have been identified over most 


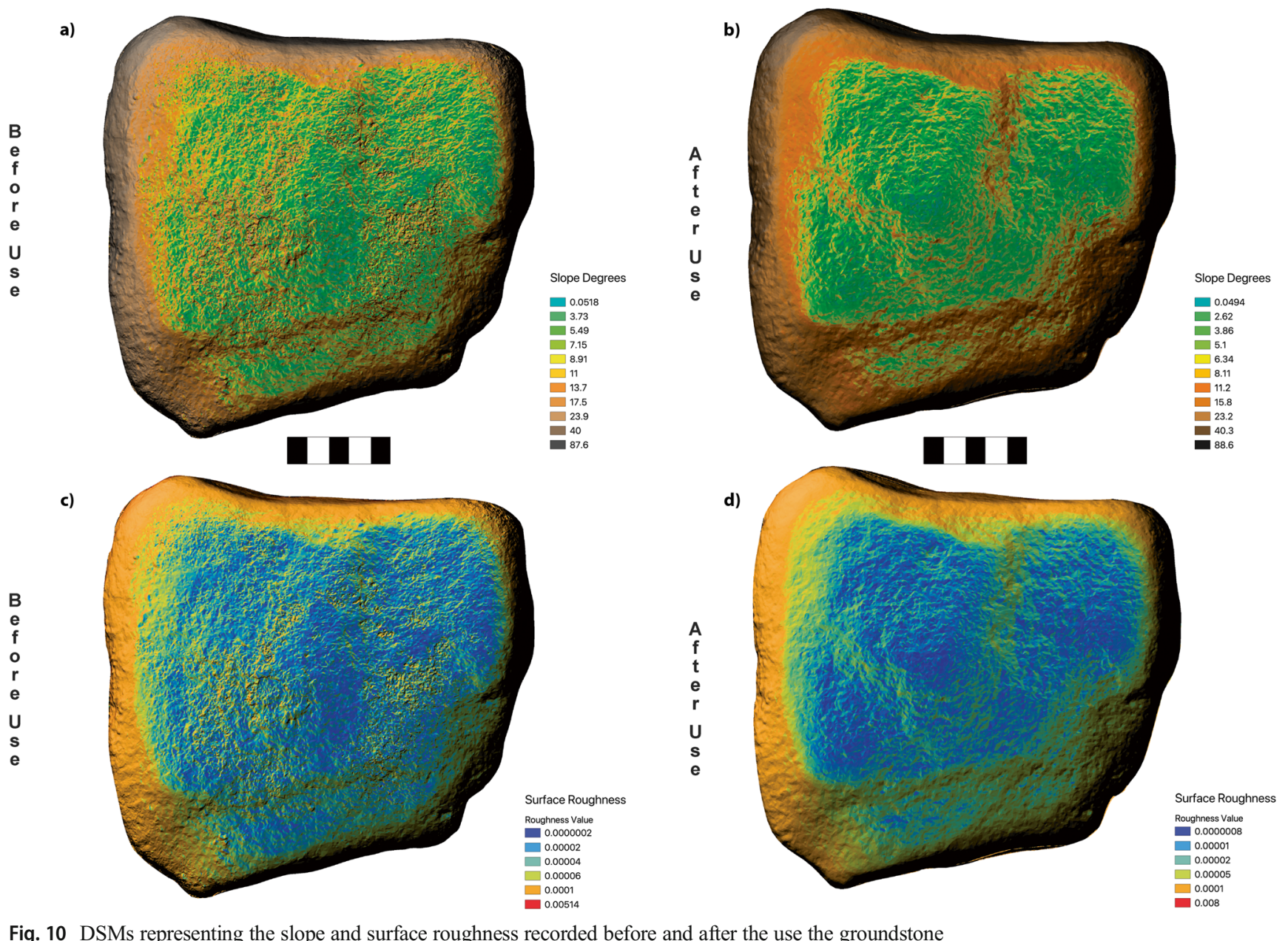

Fig. 10 DSMs representing the slope and surface roughness recorded before and after the use the groundstone

of the groundstone surface. Given the high number of identified starches, it was possible to highlight differences in the spatial distribution of intact, damaged specimens and lumps, over the tool's surface. Intact starches (n. 1787) were well spread across most of the groundstone surface (Fig. 12a, b). However, their maximum concentration was located over its lower right portion (square 6), the only area of the tool not directly involved in the grinding activity.

Concentrations of lumps (n. 252) and damaged starches (n. $524)$, instead, share the same localization over the lower central portion of the surface (square 5) while they are rare over the most utilized areas (squares 2, 3, and 4) (Fig. 12c, d). Single starches and lumps are very rare over the left corner of the groundstone (square 1). Such a paucity of granules may be related to the fact that this portion of the surface was utilized as a sort of prehensive area to keep the groundstone stable during its utilization.

\section{Experiment no.26—wild oat (Avena sterilis)}

\section{Surface morphometric analysis}

At its natural state, the surface of experiment n. 26 is characterized by the presence of low and intermediate slopes (mean $12.9^{\circ}$ ) (Fig. 13a). A step, running across the center of the tool's surface, exhibits slopes ranging between $7.1^{\circ}$ and $13.5^{\circ}$. The upper portion of the surface exhibits a gentle relief topography, in particular over its right-hand area, while, on the contrary, the lower portion of the surface is characterized by frequent low and intermediate slopes.

After being used, a decrease in the mean slope value was recorded, from $12.9^{\circ}$ to $11.4^{\circ}$. Most of the low slopes which were visible on the surface before its use disappeared or were heavily leveled as in the case of the concentration of intermediate slopes present below the step. The latter were also modified by 


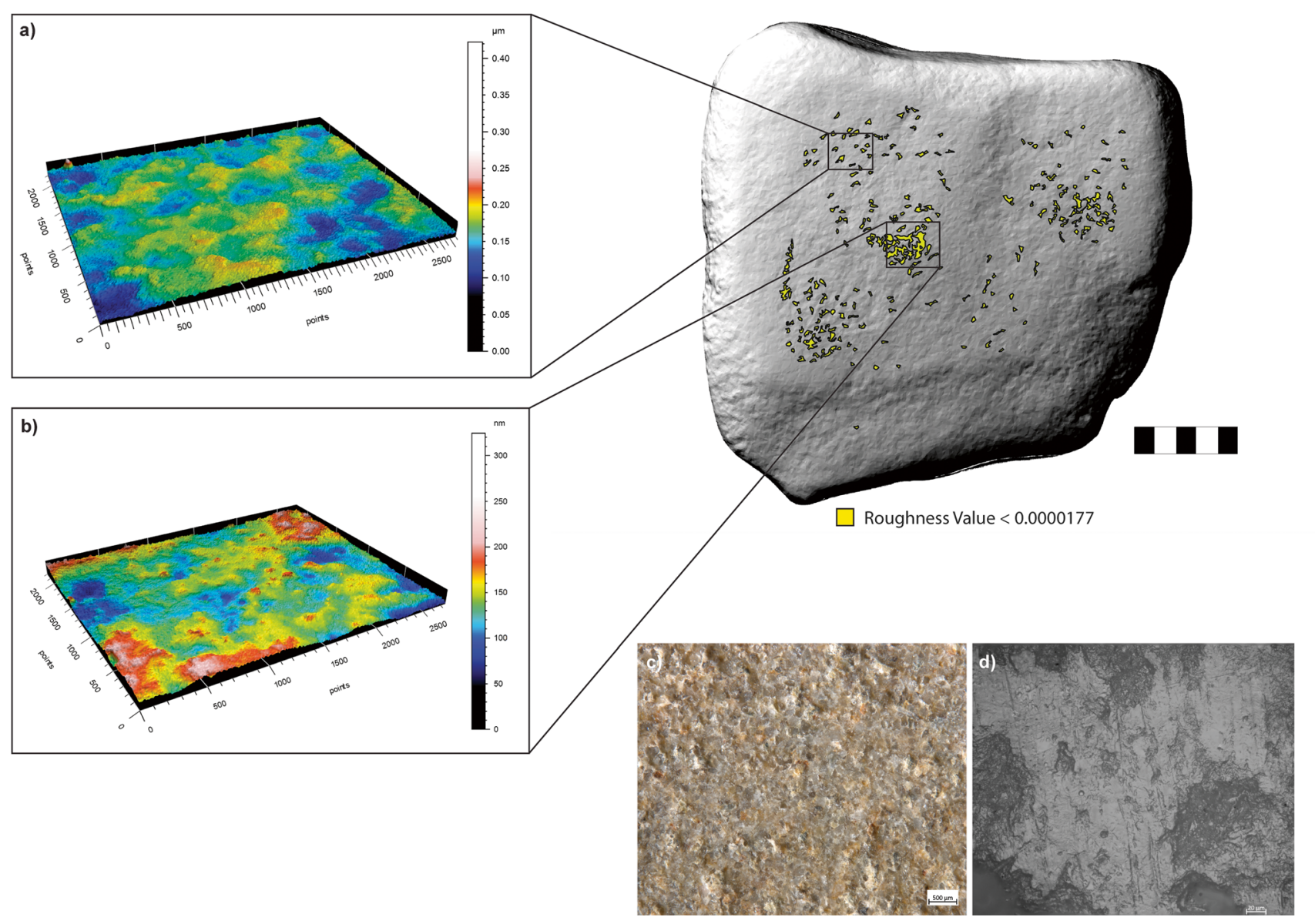

Fig. 11 Low roughness areas larger than $10 \mathrm{~mm}^{2}$ developed over the groundstone surface after its use to process Foxtail millet grains (Setaria italica). a, b $3 \mathrm{D}$ rendering of the low roughness areas observed at 50x. c, d Surface leveling and polish observed at 80x and 200x magnifications

use, especially in its central portion which exhibits values ranging between $5.5^{\circ}$ and $11.6^{\circ}$ (Fig. 13b).

Before being used, the topography of the surface appeared heterogeneous (mean value 0.00019), with more homogeneous area localized over the top right portion of the groundstone. After its use, an increase in the overall topographic homogeneity of the surface was recorded as indicated by the mean roughness value 0.00012 (Fig. 13c). Low roughness areas (roughness value $<0.0000256$ ) were well spread across the surface with the presence of medium sized (mean area $0.27 \mathrm{~cm}^{2}$ ) homogeneous spots densely localized over the central portion of the groundstone $\left(1.2 \mathrm{~cm}^{2}\right)$. At high magnifications, the low roughness areas appeared leveled with the presence of macro and micro cracks (Fig. 14c). Polishes exhibiting a rough to smooth texture and domed topography have been identified (Fig. 14d), along with deep chaotic striations characterized by a loose-separated distribution.

\section{Residue spatial distribution}

With the naked eye, macro residues are mostly packed over the central area of the surface. A total of 345 compounds have been identified over the surface of the groundstone. These are mostly localized (n. 195) over the lower left corner of the tool (square 4), which corresponds to the area less utilized during the grinding of Avena sterilis. On the contrary, very few compounds have been identified over the other portions of the surface (squares 2, 3, 5, and 6), which have been mostly utilized during the grinding activity (Fig. 15a-d). Here, a very large number of damaged starches was recorded (theoretical n. 5726), in particular in squares 5 (n. 3800) and 2 (theoretical n. 800).

\section{Discussion}

To date, the potential of 3D modeling and GIS software to analyze surface modification patterns on groundstones 


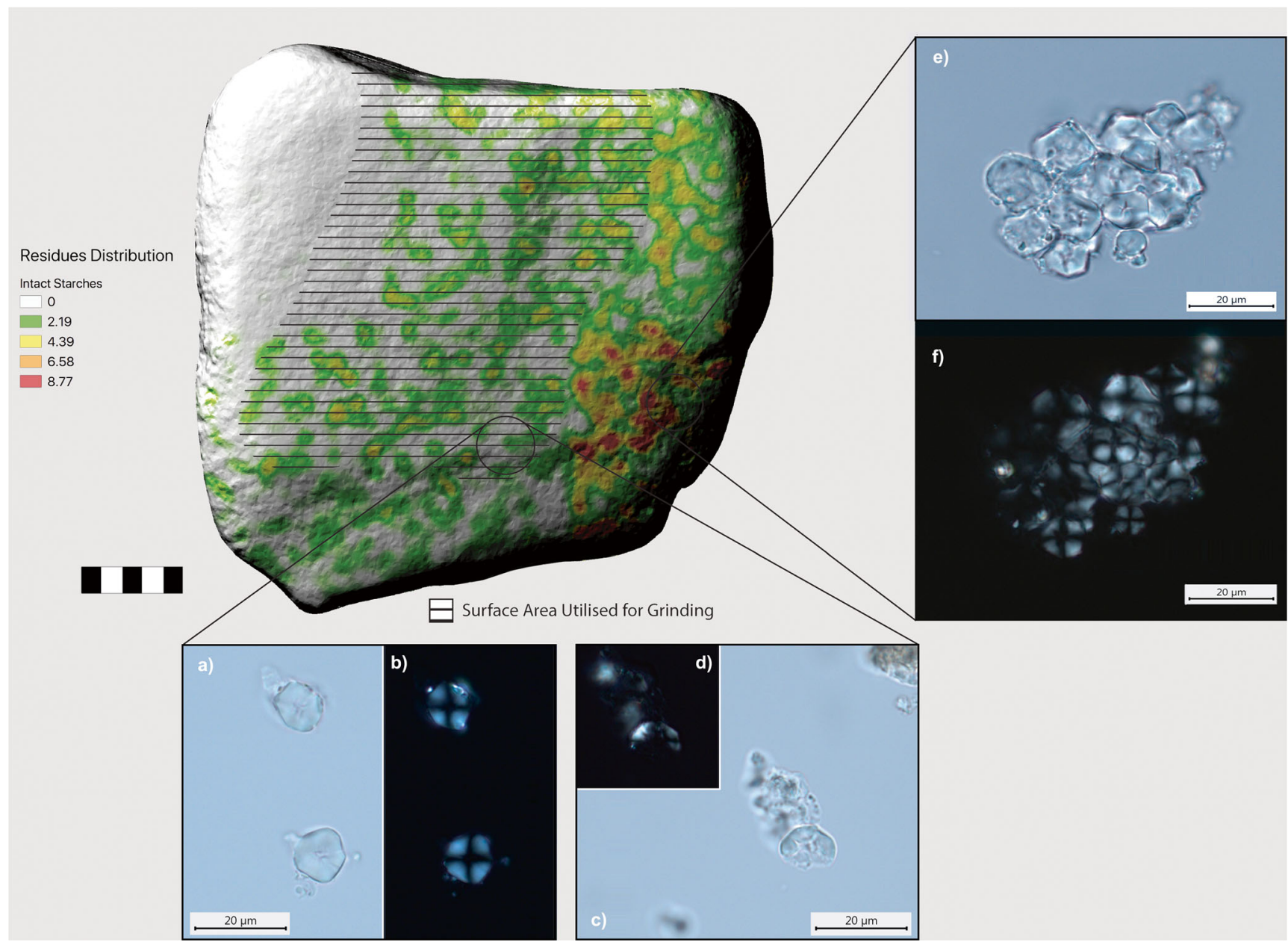

Fig. 12 Starch granule disposition over the surface of the groundstone utilized to grind Foxtail millet grains (Setaria italica). a, b Isolated starch grains with a polyhedral shape and centric hilum. c, d Single damaged

utilized to work with wild plants has been underestimated. There are also only few applications of GIS to study the distribution of residues over the surface of macro lithic tools. Despite the limited number of experiments and the need for further trials in order to monitor variables which may affect surface modification and residues' disposition on groundstone surfaces, our combined approach allowed us to identify several variations in patterns of surface modification and in the distribution of residues caused by grinding/pounding activities (Table 6).

Overall, each of the macro lithic tools suffered a leveling of the surface, which happened at different degrees (Fig. 16d). The processing of Rumex crispus (curly dock) fruits led to a loss of $0.9^{\circ}$ in the overall surface slope. This phenomenon is related to the development of the largest (mean area $0.5 \mathrm{~cm}^{2}$ ) low roughness areas identified within the experimental sample. When observed at high magnifications, the latter ones correspond to portions of the starch granules. e, f Lump of polyhedral starch granules. Notice the strong birefringence of the granules in polarized light

surface where the grains amalgamate, and a smooth domed polish developed over their upper parts.

The groundstone utilized to process Avena sterilis (wild oat) grains exhibited the highest amount in slope decrease $\left(1.5^{\circ}\right)$, which corresponds to a very high degree of leveling of the topographic asperities present across the surface. Even though it features the higher degree of surface leveling, the visible low roughness areas are different if compared to the ones generated by the grinding of curly dock fruits. These are indeed smaller (mean area $0.3 \mathrm{~cm}^{2}$ ) and well dispersed over the utilized area of the groundstone (density $0.7 \mathrm{~cm}^{2}$ ). Also, when observed at high magnification, differences are visible in terms of use wear (Table 7). In particular, macro-fractures, which were not observed on the groundstone utilized to process curly dock fruits, characterize the utilized area of experiment 26. These are probably produced by the regular contact between the groundstone and the hammerstone during use, which 


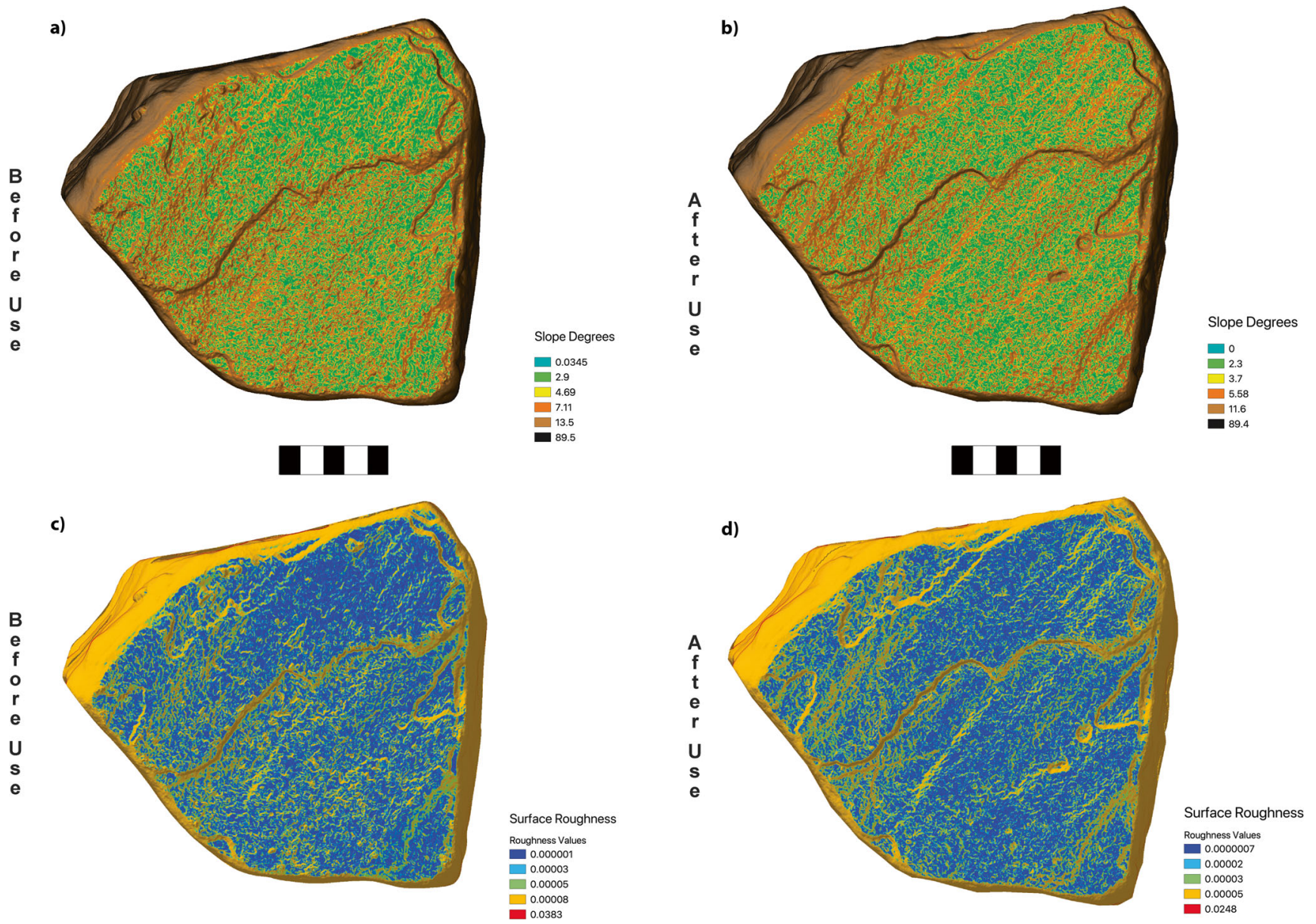

Fig. 13 DSMs of the slope and surface roughness recorded before and after the use of the groundstone

also led to the displacement of grains all across the groundstone surface. Such friction most probably also affected the morphology and dimensions of the identified low roughness areas, which would explain their differences in dimensions from the ones developed by grinding curly dock fruits.

Along with wild oat, also foxtail millet (Setaria italica) grinding led to one of the highest recorded decreases in the overall slope value $\left(1.2^{\circ}\right)$. However, despite the significant leveling of the topographic asperities present over the surface, and contrary to what was observed in the case of experiments nos. 4-A and 26, the variations in surface roughness is minimum. A further difference is given by the distribution of the low roughness areas over the groundstone surface (density $0.2 \mathrm{~cm}^{2}$ ). Moreover, the dimensions of low roughness areas are small (mean area $0.03 \mathrm{~cm}^{2}$ ) if compared to the ones generated by the grinding of wild oat and curly dock fruits. Such a difference should be researched not in the worked substance, but more likely in the gestures performed during its processing: an alternation of thrusting and resting percussion, with the former being mostly applied, which caused the spot-like distribution and the morphology of the identified low roughness areas.

Another difference from the surface modification patterns caused by the processing of Rumex crispus and Avena sterilis is found when analyzing the low roughness areas identified on experiment 13 at high magnifications, which exhibits a polish topography (flat and cratered) different from the one observed on experiments 4-A and 26 (domed).

Further evidence, strengthening the assumption of a direct, ongoing, relation between gestures employed and the development of low roughness areas, are provided by the analysis of the groundstone utilized to work the Rumex crispus roots and Quercus pubescens (experiments 4-B and 5). During both experiments, the substances were pounded before being ground. After being 


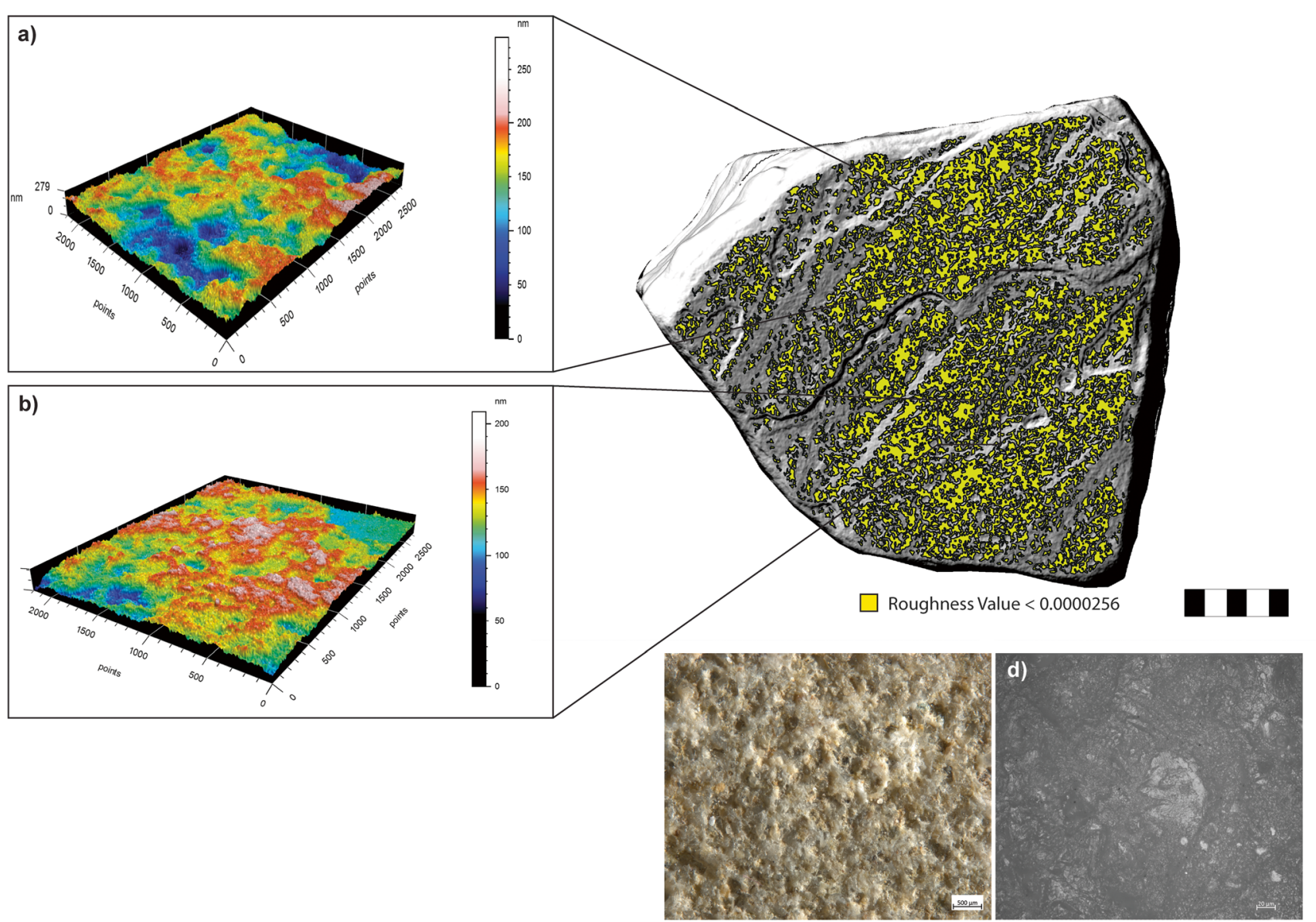

Fig. 14 Low roughness areas larger than $10 \mathrm{~mm}^{2}$ developed over the surface of the groundstone after its use. a, b 3D rendering of the low roughness areas observed at 50x. c, d Use wear identified over the low roughness areas observed at 80x and 200x

used, common surface modification patterns were observed on both of the groundstones:

- namely the absence or sporadic presence of low roughness areas across the portion of the surface utilized to pound

- an increase in the overall slope value, $0.5^{\circ}$ in the case of experiment 4-B and 0.1 in the case of experiment 5 .

- increased surface roughness limited to the areas of the surface where the pounding took place.

The areas where the roots and acorns were crushed suffered the development of new depressions on both groundstones. These led to an increase of surface heterogeneity over these portions of the groundstone surface, where low roughness areas were sporadic and very small. On the contrary, the areas, where the plant materials were ground after being pounded, are characterized by an increase in surface homogeneity indicated by the overall leveling of the topography and the appearance of low roughness areas. When compared, the dimensions of the low roughness areas associated to curly dock root grinding are bigger (mean area $0.3 \mathrm{~cm}^{2}$ ) than the ones originated by acorn (mean area $0.002 \mathrm{~cm}^{2}$ ). Differences are present also in their distribution over the groundstone surface, with a higher density $\left(1.3 \mathrm{~cm}^{2}\right)$ exhibited by the low roughness areas associated with the processing of Rumex crispus roots, than the ones related to the processing of Quercus pubescens acorns $\left(0.4 \mathrm{~cm}^{2}\right)$.

A further mean of differentiation is provided by the polishes observed at high magnification over the low roughness areas developed after use, in particular in relation to their topography (Table 6). Indeed, while in both cases the polish texture is smooth, a flat topography characterizes the polish related to curly dock root processing while a domed one is associated with acorns. 


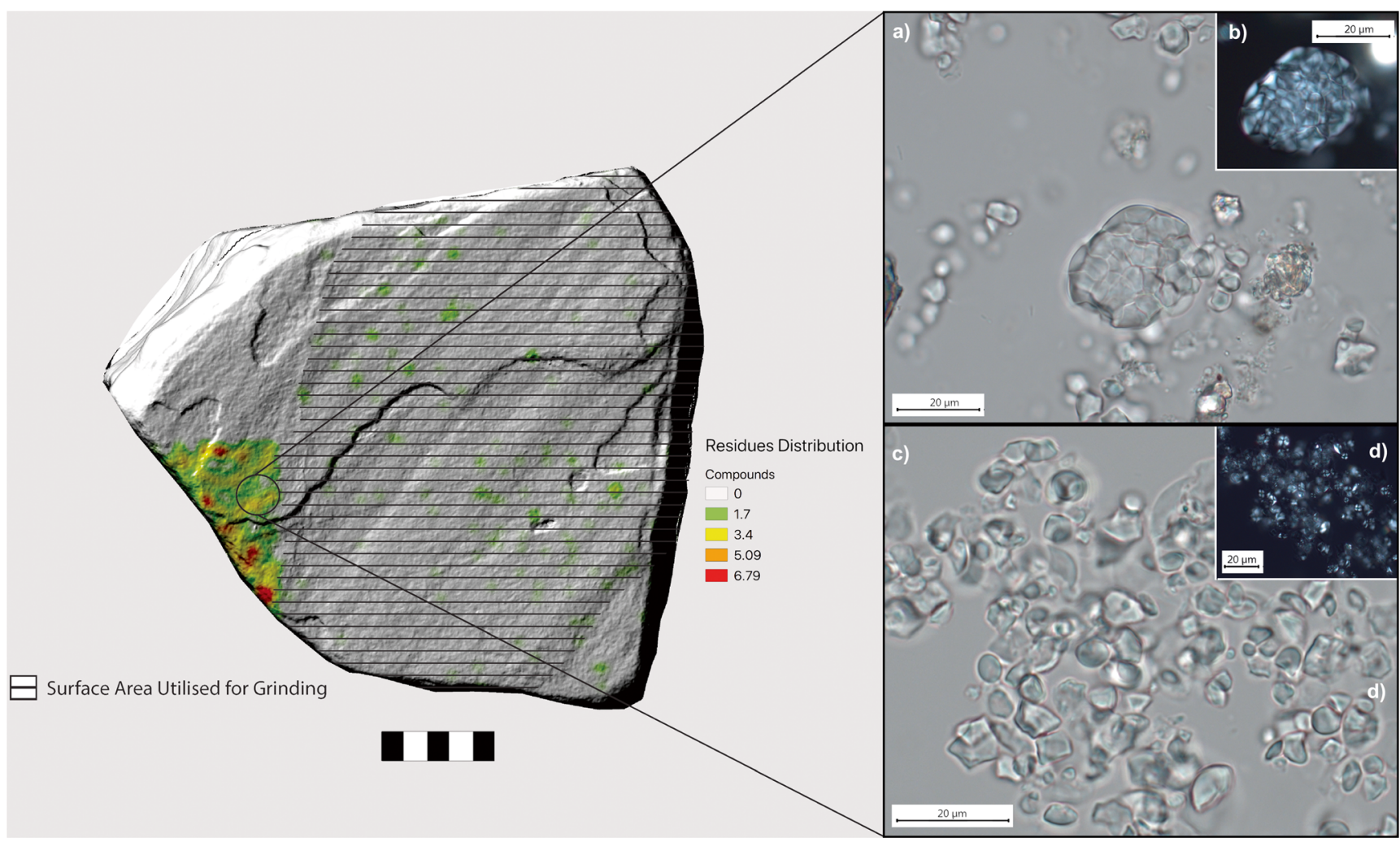

Fig. 15 Residue distribution over the groundstone surface after being used to process wild oat. Notice the general absence of compound associated to the less utilized areas. a, b Compound of round shaped starch grains, surrounded by single grains with centric hilum. c, d Single grains with clear extinction cross visible good extinction cross visible in polarized light
Moreover, relevant insights associated to the relation ongoing between gesture performed and surface morphology are obtained by quantifying the area of the groundstones' surface affected by use. Indeed, it is relevant to note how pounding activities lead to an overall low percentage of surface area affected by use wear (Table 6). This can be explained by the fact that the gesture applied is more punctual and thus the area

Table 6 Main morphometric variables of low roughness areas and variation in the overall slope value recorded on the groundstone surfaces after being used

\begin{tabular}{|c|c|c|c|c|c|c|c|c|c|c|c|}
\hline \multirow{2}{*}{$\begin{array}{l}\text { Experiment } \\
\#\end{array}$} & \multirow[t]{2}{*}{ Activity } & \multirow[t]{2}{*}{ Worked material } & \multicolumn{8}{|c|}{ Low roughness areas morphometric variables } & \multirow{2}{*}{$\begin{array}{l}\text { Slope } \\
\text { variation }\end{array}$} \\
\hline & & & $\begin{array}{l}\text { Min. } \\
\left(\mathrm{cm}^{2}\right)\end{array}$ & $\begin{array}{l}\text { Avg. } \\
\left(\mathrm{cm}^{2}\right)\end{array}$ & $\begin{array}{l}\text { Max. } \\
\left(\mathrm{cm}^{2}\right)\end{array}$ & Count & $\begin{array}{l}\text { Low } \\
\text { roughness } \\
\text { surface } \\
\left(\mathrm{cm}^{2}\right)\end{array}$ & $\begin{array}{l}\text { Groundstone } \\
\text { surface }\left(\mathrm{cm}^{2}\right)\end{array}$ & $\begin{array}{l}\% \text { of surface } \\
\text { affected } \\
\text { by use wear }\end{array}$ & $\begin{array}{l}\text { Density } \\
\left(\mathrm{cm}^{2}\right)\end{array}$ & \\
\hline $4-\mathrm{A}$ & Grinding & $\begin{array}{l}\text { Rumex crispus } \\
\text { fruits }\end{array}$ & 1 & 0.5 & 6.4 & 77 & 39.3 & 274.8 & $14 \%$ & 2.8 & $-0.9^{\circ}$ \\
\hline 4-B & $\begin{array}{l}\text { Pounding and } \\
\text { Grinding }\end{array}$ & $\begin{array}{l}\text { Rumex crispus } \\
\text { roots }\end{array}$ & 1 & 0.3 & 1.26 & 42 & 12.2 & 274.8 & $4 \%$ & 1.3 & $0.5^{\circ}$ \\
\hline 5 & $\begin{array}{l}\text { Pounding and } \\
\text { Grinding }\end{array}$ & $\begin{array}{l}\text { Quercus } \\
\text { pubescens } \\
\text { fruits }\end{array}$ & 1 & 0.002 & 14.3 & 343 & 7.87 & 225.6 & $3 \%$ & 0.4 & $0.1^{\circ}$ \\
\hline 13 & Grinding & $\begin{array}{l}\text { Setaria italica } \\
\text { grains }\end{array}$ & 1 & 0.027 & 0.4 & 206 & 5.63 & 302.7 & $2 \%$ & 0.2 & $-1.2^{\circ}$ \\
\hline 26 & Grinding & $\begin{array}{l}\text { Avena sterilis } \\
\text { grains }\end{array}$ & 1 & 0.27 & 42.8 & 427 & 116.5 & 359 & $32 \%$ & 0.7 & $-1.5^{\circ}$ \\
\hline
\end{tabular}




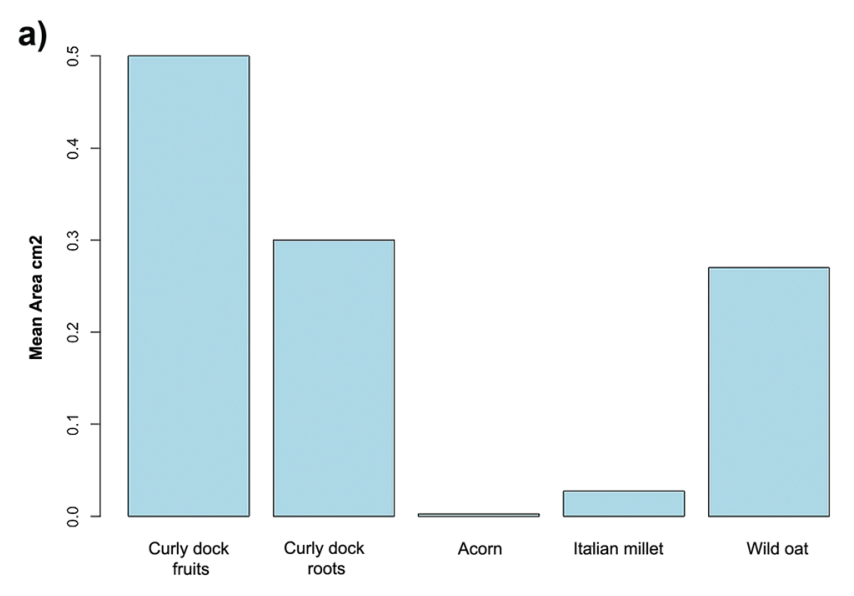

b)

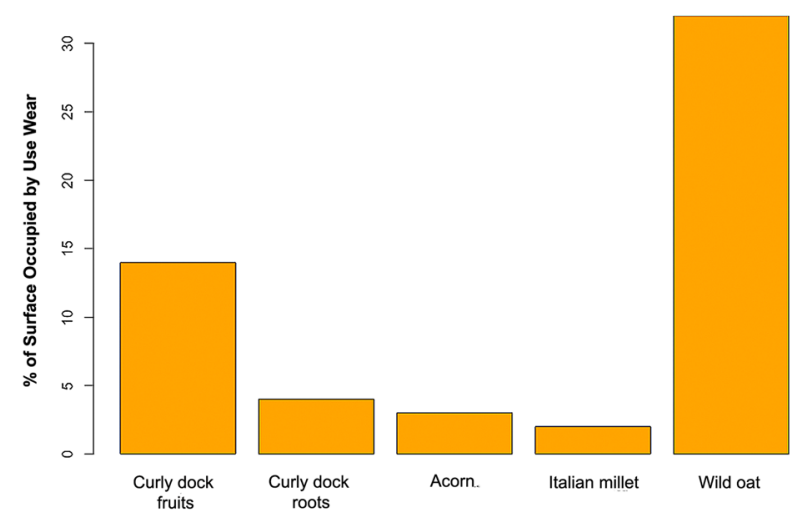

c)
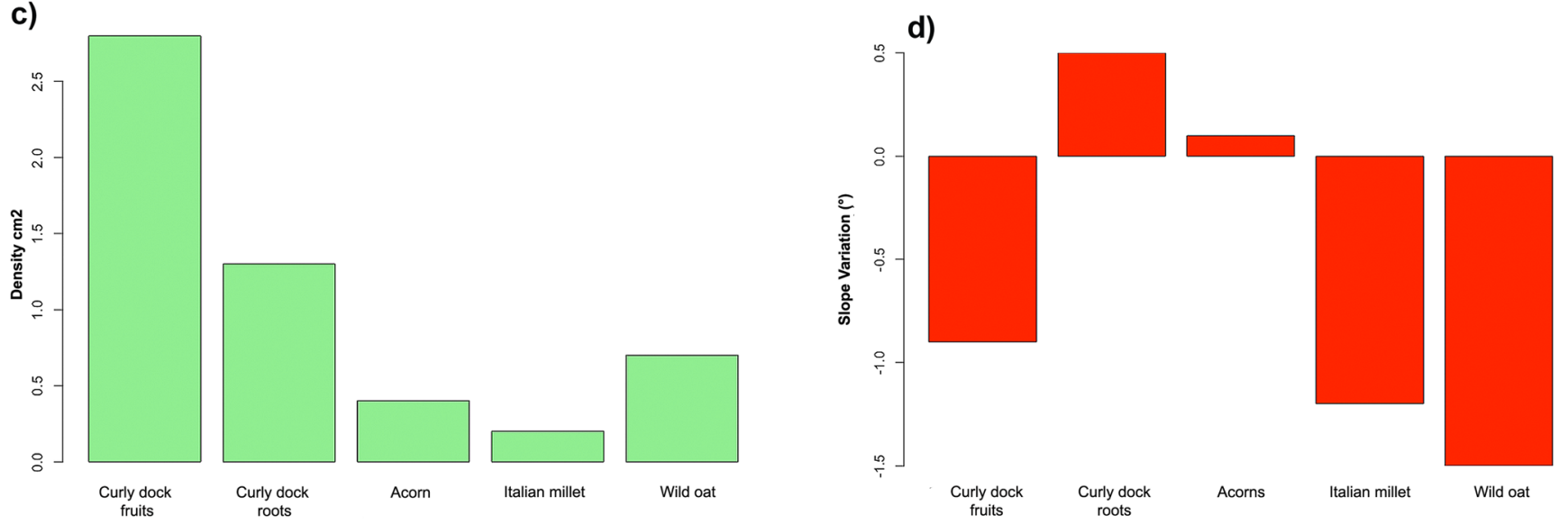

Fig. 16 Barplot related to the a dimensions of the low roughness areas; $\mathbf{b}$ percentage of the groundstone surface affected by use wear; $\mathbf{c}$ density of the low roughness areas across the groundstone surface; $\mathbf{d}$ variation in slope after the use of the groundstone

of contact between the hammerstone and the groundstone surface is limited if compared to a grinding activity. However, we noted how also the surface morphology itself affects the amount of used are of the groundstone. Indeed, as the case of experiment 13, the percentage of used surface area equals only to the $3 \%$ of the entire groundstone surface area, despite the activity performed was grinding. Such a low amount of used area can be explained by the fact that the portion of the surface utilized to ground Italian millet was convex, thus leading to a limited amount of surface coming in contact with the grinder.

Overall, the analysis of slope and surface roughness before and after use allowed to accurately monitor the degree of modification of the groundstone surfaces caused by different gestures and worked materials. Important data are also obtained by the morphometric characteristics of the low roughness (polished) areas developed over the used portions of the groundstones. In particular dimensions and density of the polished areas are characters which can provide useful data regarding the gesture performed and the processed element (fruits, grains or root) of the exploited wild plant. However, if on the one hand, the application of geomatic techniques, such as 3D and GIS, facilitates the analysis of the entire surface of a generally large tool such as groundstones, allowing to identify areas potentially modified by use, on the other hand, it is important to underline the fact that the quantitative data alone does not allow to make a distinction at a species level of the exploited wild plants. Indeed, this is only possible through the analysis of the morphological characteristics of use wear, in particular micro wear, observed at high magnification $(\geq 100 \times)$. Features as polish topography and texture, the orientation of micro striae and their depth, the shape of micro-pits, permit to identify the species of exploited wild plants along with further details concerning the gestures involved. This allows to stress how important it is to combine both quantitative and qualitative data to provide a correct and detailed interpretation, and its 
potentials in providing new insights regarding the use of groundstones and pounding tools.

Concerning residue spatial distribution, our analysis revealed a lack of correspondence between the overall distribution of macro residues observed at the naked eyes just after use and the spatial concentration of diagnostic specimens (intact starch granules and compounds). Concentration (i.e., hotspots) of intact residues and compounds was influenced by the activity performed. Indeed, over the surface of groundstones utilized for grinding activities, hotspots of intact starches and compounds are localized at the periphery the utilized surface portion. The disposition of residues outside the utilized area of the tool is due to two main factors. First of all, the back and forth movements performed during grinding favor a sideways displacement of residues across the surface. Secondly, the high degree of homogeneity (i.e., absence of topographic variations due to the modification of the intergranular space) characterizing the utilized areas made the entrapment of starch granules (and residues in general) not easy. On the contrary, the presence of topographic asperities (i.e., depression and pits) and the higher heterogeneity of the areas outside the used surface portion favored the embedding of starch granules. This would explain the high frequency of intact starch granules, over the areas of the surface where pounding activities took place. Indeed, in these areas, the gestures performed during pounding led to an increase of surface heterogeneity given the development of depressions and pits, which facilitated the entrapment and preservation of residues. A similar behavior is observed when the distance between intact starches and low roughness (i.e., polished) areas of the surface is computed. In general, intact starches and compounds are localized in proximity of the polished areas. However, a difference between the disposition of residues associated to grinding and the ones related to pounding do exist, with the latter (mean dist. $2 \mathrm{~cm}$ ) localized farther from the polished areas than the formers (mean dist. $1 \mathrm{~cm}$ ) (Table 8) (Fig. 17a).

The spatial relation between diagnostic plant residues (single starches and compounds) and polished areas of the surface is further suggested when the distance between intact starches/compounds and surface low roughness areas is calculated making a distinction between the wild plant species processed (Fig. 17b). Overall, intact starches and compounds are localized relatively close to the polished area of the groundstone surface (mean dist. $\sim 1 \mathrm{~cm}$ ), with the exception of Rumex crispus roots and Setaria italica, where intact specimens are found also at a higher distance from the low roughness areas developed over the utilized surface (mean dist. $1.5 \mathrm{~cm}$ and $2 \mathrm{~cm}$ respectively) (Table 7) (Fig. 17b). 
Table 8 Distances occurring between the localization of intact starch granules and compounds with the low roughness (polished) areas developed after use over the utilized groundstone surface

\begin{tabular}{llllll}
\hline Worked material & Min. (cm) & Mean. (cm) & Max. (cm) & Count (n.) & Activity \\
\hline Rumex crispus fruits & 0 & 0.5 & 3 & 104 & Grinding \\
Rumex crispus roots & 0 & 2 & 5 & 1146 & Pounding \\
Quercus pubescens & 0 & 0.6 & 3 & 1118 & Pounding and grinding \\
Setaria italica & 0 & 1.5 & 5 & 1772 & Grinding \\
Avena sterilis & 0 & 0.1 & 1 & 324 & Grinding \\
\hline
\end{tabular}

In this particular case, if for curled dock (exp. 4b) roots, the displacement of intact starches far from the polished areas of the surface can be attributed to the activity performed (i.e., pounding), a different reason might be proposed in regard to Italian millet (exp. 13). Indeed, in the latter case, the localization of intact starch granules away from the low roughness areas generated by use can be explained by the morphology of the functional area (i.e., slightly convex), rather than by the activity performed (i.e., grinding), which affected the distribution of residues across the surface.

This example indicates that if the gesture performed plays a major role in the displacement of starch granules over the groundstone surface (Fig. 17a), attention also needs to be given to the morphological features of the utilized functional area that might as well contribute to the spatial distribution of residues over the tool's surface.

To the best of our knowledge, our study represents one of the first attempts to evaluate the potential of 3D scanning and GIS software in combination with use wear and residue analyses in the study of groundstones involved in wild plant processing.

Despite a limited size of our experimental sample, our results emphasize the spatial relation occurring between use wear and starch granules, overall contributing to the debate regarding the potential of ancient starch granules in interpreting groundstone use (e.g., Mercader et al. 2018). The methodological approach presented herein underlines even more the importance of combining use wear and residue analyses in order to provide an adequate interpretation of the use of groundstone, in particular regarding their exploitation in plant processing. Overall, this paper defined the potentials of this combined methodological framework; however, for the scope of this study, it remained limited to the analysis of passive elements and to the spatial distribution of starch granules. In future studies which are currently in progress as a part of the HIDDEN FOODS project, we aim to broaden our focus to the analysis of active elements (pounders/ crushers) and to analyze the spatial distribution of other kinds of residues such as animal, mineral, and vegetal (pollens and phytolites) processed at different states (dry, wet etc.) and through different activities. This will allow to refine our methods of analysis, through the use of other kind of equipment (e.g., confocal microscope) and provide new means which could enhance our current knowledge on residues and use wear analyses of archeological macro lithic tools.

\section{Conclusions}

In this paper, we presented the data achieved through the application of a methodological approach comprising an integration of 3D modeling, GIS software, use wear, and residue analyses. Through the analysis of a set of experimental macro lithic tools, it was possible to observe and quantify patterns of surface modifications along with residues' spatial distribution related to the processing of wild plants. We were able to demonstrate both from a qualitative and quantitative point of view how different activities and gestures variably affect surfaces of macro lithic tools used to process wild plants. Back and forth movements performed during the grinding of grains, roots, and nuts favored the leveling of topographic asperities, leading to the development of low roughness areas across the utilized areas of the tools. On the contrary, pounding gestures led to the crushing of specific surface portions and the production of depressions and pits. The combination of gestures performed during the activity and surface modifications also play a major role in the displacement of residues over the surface of macro lithic tools. Indeed, residues are more likely to be localized outside the utilized area of the tool when grinding is performed. The opposite situation is observed with regard to pounding activities, which mostly led to the displacement of residues over the utilized portion of the worked tools. Overall, our results permit us to quantify and differentiate the amount of surface modification affecting groundstones involved in the processing of different plant foods, such as wild grass fruits, acorns, and roots. Our data also demonstrate how a systematic combination of use wear, spatial analysis, and likelihood of preservation of starch granules in specific functional areas of the tool can reduce the risk of contamination, thus avoiding false interpretations of archeological groundstone use. 

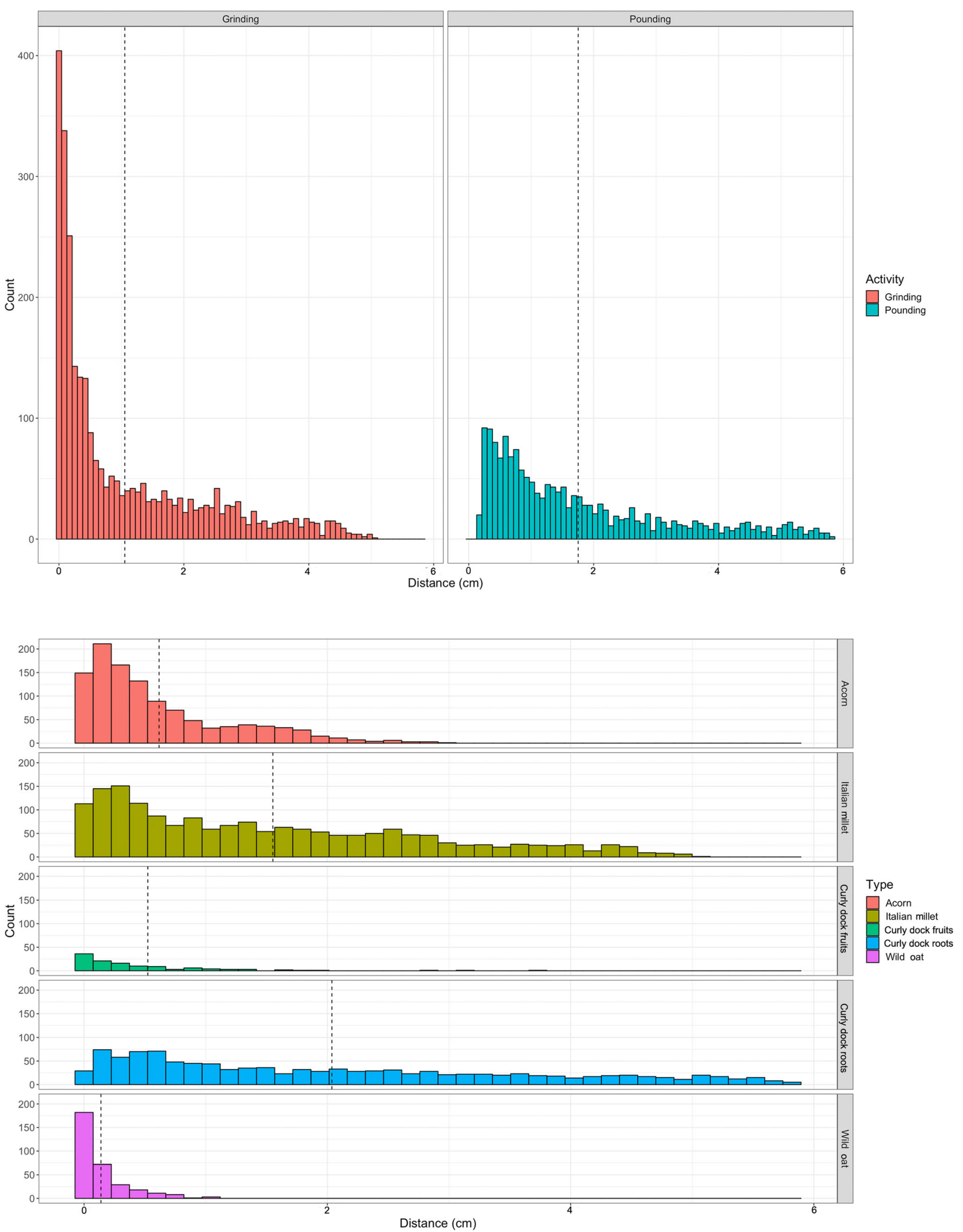

Fig. 17 Histograms showing the distances between intact starches/compounds and the low roughness (polished) areas of the utilized groundstone surface. a Distance compute by activity performed. b Distances compute by species of processed plant 
Acknowledgments We are grateful to Carmine Gallo for his help in the gathering of raw materials and Giovanni Morra for his assistance in the gathering of the wild plant specimens used in the experimental trials.

Authors' contributions $\mathrm{AZ}, \mathrm{IC}$, and EC conceived and planned the project; AZ, IC, GM, AR and EC performed the analytical work and data interpretation; AZ performed 3D scanning and spatial analysis; IC performed use wear analysis; EC, GM, and AR performed residue analysis; MLC performed the experimental activities. EC supervised the project. All the authors contributed to the writing of the manuscript.

Funding Funding was received for this project through the European Research Council (ERC Starting Grant Project HIDDEN FOODS, G.A. 639286 to EC).

Open Access This article is distributed under the terms of the Creative Commons Attribution 4.0 International License (http:// creativecommons.org/licenses/by/4.0/), which permits unrestricted use, distribution, and reproduction in any medium, provided you give appropriate credit to the original author(s) and the source, provide a link to the Creative Commons license, and indicate if changes were made.

\section{References}

Adams JL (2014a) Ground stone use-wear analysis: a review of terminology and experimental methods. J Archaeol Sci 48:129-138

Adams JL (2014b) Ground stone analysis: a technological approach. University of Utah Press, Salt Lake City

Arriaza MC, Yravedra J, Domínguez-Rodrigo M, Mate-González MÁ, García Vargas E, Palomeque-González JF, Aramendi J, GonzálezAguilera D, Baquedano E (2017) On applications of microphotogrammetry and geometric morphometrics to studies of tooth mark morphology: the modern Olduvai Carnivore Site (Tanzania). Palaeogeogr Palaeoclimatol Palaeoecol 488:103-112. https://doi. org/10.1016/j.palaeo.2017.01.036

Arroyo A, de la Torre I (2016) Assessing the function of pounding tools in the Early Stone Age: a microscopic approach to the analysis of percussive artefacts from beds I and II, Olduvai Gorge (Tanzania). J Archaeol Sci 74:23-34. https://doi.org/10.1016/j.jas.2016.08.003

Atchison J, Fullagar R (1998) Starch residues on pounding implements from Jinmium rock-shelter. In: Fullagar R (ed) A closer look: recent Australian studies of stone tools. Archaeological Computing Laboratory, University of Sydney, Sydney, pp 109-125

Banks WE, Kay M (2003) High resolution casts for lithic use-Wear analysis. Lithic Technol 28(1):27-34

Barton H, Torrence R (2015) Cooking up recipes for ancient starch: assessing current methodologies and looking to the future. J Archaeol Sci 56:194-201

Benito-Calvo A, Carvalho S, Arroyo A, Matsuzawa T, de la Torre I (2015) First GIS analysis of modern stone tools used by wild chimpanzees (pan troglodytes verus) in Bossou, Guinea, West Africa. PLoS One 10(3):e0121613. https://doi.org/10.1371/journal.pone. 0121613

Benito-Calvo A, Arroyo A, Sánchez-Romero L, Pante M, de la Torre I (2017) Quantifying 3D micro-surface changes on experimental stones used to break bones and their implications for the analysis of early stone age pounding tools. Archaeometry. https://doi.org/10. $1111 /$ arcm. 12325

Benito-Calvo A, Crittenden AN, Livengood SV, Sánchez-Romero L, Martínez-Fernández A, de la Torre I, Pante M (2018) 3D 360 surface morphometric analysis of pounding stone tools used by Hadza foragers of Tanzania: a new methodological approach for studying percussive stone artefacts. J Archaeol Sci Rep 20:611-621. https:// doi.org/10.1016/j.jasrep.2018.06.003

Bofill M, Procopiou H, Vargiolu R, Zahouani H (2013) Use-wear analysis of near eastern prehistoric grinding stones. Regards croisés sur les outils liés au travail des végétaux, pp 225-242

Bretzke K, Conard NJ (2012) Evaluating morphological variability in lithic assemblages using 3D models of stone artifacts. J Archaeol Sci 39(12):3741-3749. https://doi.org/10.1016/j.jas.2012.06.039

Caricola I, Zupancich A, Moscone D, Mutri G, Falcucci A, Duches R, Peresani M, Cristiani E (2018) An integrated method for understanding the function of macro-lithic tools. Use wear, 3D and spatial analyses of an early upper palaeolithic assemblage from North Eastern Italy. PloS One 13(12). https://doi.org/10.1371/journal. pone. 0207773

Caruana MV, Carvalho S, Braun DR, Presnyakova D, Haslam M, Archer W, Bobe R, Harris JWK (2014) Quantifying traces of tool use: a novel morphometric analysis of damage patterns on percussive tools. PLoS One 9(11):1-18. https://doi.org/10.1371/journal.pone. 0113856

Chacòn MG, Détroit F, Coudenneau A, Moncel M-H (2016) Morphometric assessment of convergent tool technology and function during the early middle Palaeolithic: the case of payre, France. PLoS One 11(5):1-20. https://doi.org/10.1371/journal.pone. 0155316

Conte IC, Fernández TL, Astruc L, Rodríguez AR (2015) Use-wear analysis of nonflint lithic raw materials: the cases of quartz/quartzite and obsidian. In: Use-wear and residue analysis in archaeology. Springer, Cham, pp 59-81

Cristiani E, Radini A, Edinborough M, Borić D (2016) Dental calculus reveals Mesolithic foragers in the Balkans consumed domesticated plant foods. Proc Natl Acad Sci 113(37):10298-10303

Crowther A, Haslam M, Oakden N, Walde D, Mercader J (2014) Documenting contamination in ancient starch laboratories. J Archaeol Sci 49(1):90-104. https://doi.org/10.1016/j.jas.2014.04. 023

de Beaune SA (2004) The invention of technology. Curr Anthropol 45(2): 139-162. https://doi.org/10.1086/381045

de la Torre I, Benito-Calvo A, Arroyo A, Zupancich A, Proffitt T (2013) Experimental protocols for the study of battered stone anvils from Olduvai Gorge (Tanzania). J Archaeol Sci 40(1):313-332. https:// doi.org/10.1016/j.jas.2012.08.007

Dubreuil L, Savage D (2014) Ground stones: a synthesis of the use-wear approach. J Archaeol Sci 48:139-153

Dubreuil L, Savage D, Delgado-Raack S, Plisson H, Stephenson B, De La Torre I (2015) Current analytical frameworks for studies of usewear on ground stone tools. In: Use-wear and residue analysis in archaeology. Springer, Cham, pp 105-158

Evans A, Donahue RE (2008) Laser scanning confocal microscopy: a potential technique for the study of lithic microwear. J Archaeol Sci 35:2223-2230

Field J, Cosgrove R, Fullagar R, Lance B (2009) Starch residues on grinding stones in private collections: a study of morahs from the tropical rainforests of NE Queensland. Archaeological science under a microscope studies in residue and ancient DNA analysis, pp 228238

Fullagar R, Field J, Kealhofer L (2008) Grinding stones and seeds of change: starch and phytoliths as evidence of plant food processing. New approaches to old stones: recent studies of ground stone artifacts, pp 159-172

González-Urquijo JE, Ibáñez-Estévez JJ (2003) The quantification of usewear polish using image analysis. First results. J Archaeol Sci 30(4): 481-489

Grosman L, Smikt O, Smilansky U (2008) On the application of 3-D scanning technology for the documentation and typology of lithic artifacts. J Archaeol Sci 35(12):3101-3110. https://doi.org/10.1016/ j.jas.2008.06.011 
Hamon C (2008) Functional analysis of stone grinding and polishing tools from the earliest Neolithic of north-western Europe. J Archaeol Sci 35:1502-1520

Haslam M (2004) The decomposition of starch grains in soils: implications for archaeological residue analyses. J Archaeol Sci 31(12): 1715-1734. https://doi.org/10.1016/j.jas.2004.05.006

Haslam M (2006) Archaeological residue and starch analysis interpretation and taphonomy. $\mathrm{PhD}$ thesis, University of Queensland

Hayes E (2015) What was ground? A functional analysis of grinding stones from Madjedbebe and Lake Mungo, Australia. PhD thesis, School of Earth and Environmental Sciences, University of Wollongong

Hayes EH, Cnuts D, Lepers C, Rots V (2017) Learning from blind tests: determining the function of experimental grinding stones through use-wear and residue analysis. J Archaeol Sci Rep 11:245-260. https://doi.org/10.1016/j.jasrep.2016.12.001

Hayes E, Pardoe C, Fullagar R (2018) Sandstone grinding/pounding tools: use-trace reference libraries and Australian archaeological applications. J Archaeol Sci Rep 20:97-114. https://doi.org/10.1016/j. jasrep.2018.04.021

Henry AG, Hudson HF, Piperno DR (2009) Changes in starch grain morphologies from cooking. J Archaeol Sci 36(3):915-922

Horrocks M, Irwin G, Jones M, Sutton D (2004) Starch grains and xylem cells of sweet potato (Ipomoea batatas) and bracken (Pteridium esculentum) in archaeological deposits from northern New Zealand. J Archaeol Sci 31(3):251-258

Ibáñez JJ, González-Urquijo JE, Gibaja J (2014) Discriminating wild vs domestic cereal harvesting micropolish through laser confocal microscopy. J Archaeol Sci 48(1):96-103. https://doi.org/10.1016/j. jas.2013.10.012

Keeley LH (1980) Experimental determination of stone tool uses: a microwear analysis. University of Chicago Press

Lippi MM, Foggi B, Aranguren B, Ronchitelli A, Revedin A (2015) Multistep food plant processing at Grotta Paglicci (Southern Italy) around 32,600 cal BP. Proc Natl Acad Sci 112(39):12075-12080

Loy TH, Spriggs M, Wickler S (1992) Direct evidence for human use of plants 28,000 years ago: starch residues on stone artefacts from the northern Solomon Islands. Antiquity 66(253):898-912

Luhmann T, Robson S, Kyle S, Boehm J (2013) Close-range photogrammetry and 3D imaging. Walter de Gruyter, Berlin

Macdonald DA (2014) The application of focus variation microscopy for lithic use-wear quantification. J Archaeol Sci 48(1):26-33. https:// doi.org/10.1016/j.jas.2013.10.003

Macdonald DA, Harman R, Evans AA (2018) Replicating surface texture: preliminary testing of molding compound accuracy for surface measurements. J Archaeol Sci Rep 18:839-846. https://doi.org/10. 1016/j.jasrep.2018.02.033

Marinova E, Filipovic D, Obradović D, Allué E (2013) Wild plant resources and land use in the Mesolithic and early Neolithic south-east Europe: Archaeobotanical evidence from the Danube catchment of Bulgaria and Serbia. Offa 69:467-478

Maté-González MÁ, Aramendi J, Yravedra J, Blasco R, Rosell J, González-Aguilera D, Domínguez-Rodrigo M (2017) Assessment of statistical agreement of three techniques for the study of cut marks: 3D digital microscope, laser scanning confocal microscopy and micro-photogrammetry. J Microsc 267(3):356-370. https://doi. org/10.1111/jmi. 12575

Maté-González MÁ, Palomeque-González JF, Yravedra J, GonzálezAguilera D, Domínguez-Rodrigo M (2018) Microphotogrammetric and morphometric differentiation of cut marks on bones using metal knives, quartzite, and flint flakes. Archaeol Anthropol Sci 10(4):805-816. https://doi.org/10.1007/s12520-0160401-5

Mercader J, Akeju T, Brown M, Bundala M, Collins MJ, Copeland L, Crowther A, Dunfield P, Henry A, Inwood J, Itambu M, Kim JJ, Larter S, Longo L, Oldenburg T, Patalano R, Sammynaiken R, Soto M, Tyler R, Xhauflair H (2018) Exaggerated expectations in ancient starch research and the need for new taphonomic and authenticity criteria. Facets 3(1):777-798. https://doi.org/10.1139/facets-20170126

Morales JI, Lorenzo C, Vergès JM (2015) Measuring retouch intensity in lithic tools: a new proposal using 3D scan data. J Archaeol Method Theory 22(2):543-558. https://doi.org/10.1007/s10816-013-9189-0

Pedergnana A, Ollé A (2017) Monitoring and interpreting the use-wear formation processes on quartzite flakes through sequential experiments. Quat Int 427:35-65. https://doi.org/10.1016/j.quaint.2016. 01.053

Piperno DR, Ranere AJ, Holst I, Hansell P (2000) Starch grains reveal early root crop horticulture in the Panamanian tropical forest. Nature 407(6806):894-897

Porter ST, Roussel M, Soressi M (2016) A simple photogrammetry rig for the reliable creation of 3D artifact models in the Field. Adv Archaeol Pract 4(01):71-86. https://doi.org/10.7183/2326-3768.4.1.71

Stemp J (2001) UBM laser Profilometry and lithic use-Wear analysis: a variable length scale investigation of surface topography. J Archaeol Sci 28:81-88

Stemp WJ (2014) A review of quantification of lithic use-wear using laser profilometry: a method based on metrology and fractal analysis. J Archaeol Sci 48(1):15-25. https://doi.org/10.1016/j.jas.2013.04.027

Torrence R, Barton H (eds) (2016) Ancient starch research. Routledge

Tringham R, Cooper G, Odell GH, Voytek B, Whitman A (1974) Experimentation in the formation of edge damage: a new approach to lithic analysis. J Field Archaeol 1:171-196

Van Gijn AL (2010) Flint in focus: lithic biographies in the Neolithic and Bronze Age. Sidestone Press, Leiden

Wright K (1992) A classification system for ground stone tools from the prehistoric Levant. Paléorient 18(2):53-81

Yang X, Perry L (2013) Identification of ancient starch grains from the tribe Triticeae in the North China Plain. J Archaeol Sci 40(8):3170 3177

Publisher's note Springer Nature remains neutral with regard to jurisdictional claims in published maps and institutional affiliations. 